\title{
Peter Paul Rubens und Franciscus Junius. Aemulatio in Praxis und Theorie
}

\author{
Nils Büttner
}

\section{In Rom zu Ruhm}

Im Mai des Heiligen Jahres 1600 war Rubens nach Italien aufgebrochen. Nur wenig später stand er nachweislich im Dienst des Mantuaner Herzogs. ${ }^{1}$ Noch im August des Jahres 1601 war er nämlich im Auftrage Vincenzo Gonzagas nach Rom gereist, vermutlich um dort in den vatikanischen Sammlungen Gemälde zu kopieren. Der Herzog hatte ihn brieflich der Obhut und dem Schutz des befreundeten Kardinals Alessandro Montalto empfohlen, den er bat, "meinen flämischen Maler" in allem auszuhelfen, dessen dieser bedürfe, um ihm zu Diensten sein zu können. ${ }^{2}$ Zudem hatte er Lelio Arrigoni, seinen in Rom residierenden Agenten in Kunstsachen, angewiesen, Rubens nach dessen Bedürfnissen mit Geld zu versehen. ${ }^{3}$ Derartige Reisen scheint Rubens von Mantua aus schon früher unternommen zu haben. Dabei besuchte er allem Anschein nach diverse italienische Städte und traf bei dieser Gelegenheit verschiedene Male seinen Bruder Philipp, der sich zu dieser Zeit ebenfalls in Italien

1 Dok. vom 8. Mai 1600. Stadsarchief Antwerpen (im Folgenden: SAA), Cert. 61 (Certificatieboek 1600), fol. 205․ Vgl. auch Büttner 2006, 170, Anm. 144.

2 "Ill ${ }^{m o}$ et $R^{m o} S^{r e}$ mio Oss ${ }^{m o}$. L'esibitore della presente sarà Piet ${ }^{\circ}$ Paolo fiamingo mio Pittore, qual mando costà per copiare, et fare alcuni quadri di pittura, come piu diffusam $^{\text {te }}$ V. Ill ${ }^{\text {ma }}$ piacendole intendera dal medesimo. Confidato al solito nella molta amorevoleza di lei, ho voluto accompagnarlo con la presente, con la quale prego V. Ill ${ }^{\mathrm{ma}}$ strettamente a favorirlo con la molta autorita sua in tutto quello che da esso lui verrà ricercata per mio servitio, che assicurandola che aggiungerò questo novo favore a tanti altri da me ricevuti dalla bonta sua, di che le vivo con infinito obligo, a me non restà a dire altro a V. Ill ${ }^{\mathrm{ma}}$ se non che questa sera sono per incaminarmi alla citta di Gratz per trasferirmi poi di là alla guerra in Croatia [...] Mantova, a, [sic] 8 di Luglio 1601. Vincenco." Rooses/Ruelens 1887-1909, Bd. 1, 28, Nr. 4.

3 Dies geht aus einer Reihe erhaltener Schreiben Arrigonis hervor. Vgl. hierzu Rooses/Ruelens 1887-1909, Bd. 1, 29, Nr. 6; 41, Nr. 8 und 49, Nr. 10. 
aufhielt. ${ }^{4}$ Philipp Rubens befand sich damals gerade auf einer Studienreise, die er gemeinsam mit Guillaume Richardot unternahm, einem Sohn des berühmten Jean Richardot, dem Vorsitzenden des Geheimen Rates der habsburgischen Niederlande. ${ }^{5}$ Ihm hatte Philipp Rubens über mehrere Jahre als Sekretär gedient und nun war er gemeinsam mit dessen Sohn auf Reisen. ${ }^{6}$ Philipp und Guillaume hatten beide dem Contubernium des Justus Lipsius angehört und als Schüler des berühmten Philosophen in dessen Hause gelebt. ${ }^{7}$ Nach Jahren des Studiums und des gemeinsamen Lebens hatte der alte Philosoph darauf gedrungen, dass seine Contubernales zum Abschluss ihrer Ausbildung eine Studienreise nach Italien unternehmen sollten. ${ }^{8}$ Tatsächlich waren die beiden dann im Herbst des Jahres 1601 aufgebrochen, um die berühmten Stätten der Antike kennenzulernen.? Daneben diente diese Reise augenscheinlich der Kontaktpflege, denn sie führte zu zahlreichen Begegnungen mit anderen Humanisten, besonders

4 Als Beleg für diverse Begegnungen der Brüder lässt sich ein beeindruckendes Bildzeugnis anführen: Peter Paul Rubens: Mantuaner Freundschaftsbild. Öl auf Leinwand, 77,5 × $101 \mathrm{~cm}$. Köln, Wallraf-Richartz-Museum, Inv.-Nr. Dep. 248. Vgl. Kat.-Ausst. Köln 1992, 405 f., Kat.-Nr. 65.1. Die gemeinsam unternommenen Reisen werden zudem durch einen Brief dokumentiert, den Philipp Rubens am 13. Dezember 1601 an seinen Bruder sandte: „Prima votorum Italiam videre, et in eâ te, mi frater; altero poitus sum, alterum in spe. Quid enim? Quantillum iter Mantuâ Patavium? Curriculo, ut ita dicam, confici poterit, cùm anni tempus feret; sed tum id videbimus." Rooses/Ruelens 1887-1909, Bd. 1, 38, Nr. 7.

$5 \mathrm{Zu}$ Richardot vgl. Heinen 2002, 315, Anm. 58, mit weiterer Literatur.

6 Biographie Nationale 1866-1986, Bd. 20, Sp. 313-317, bes. $313 \mathrm{f}$.

7 Zum Contubernium des Justus Lipsius vgl. Peeters 1999, 141-168.

8 Lipsius wandte sich an Jean Richardot, dem er den pädagogischen Nutzen einer solchen Reise schilderte, wobei er auch keinen Hehl daraus machte, dass er die für ihn aus der Abreise der Schüler entstehende Ruhe durchaus zu schätzen wüsste. Richardots Antwort auf diesen verlorenen Brief ist erhalten: „Sed angit me non mediocriter quod de meo Guilielmo sciscitaris. Nam nec tibi vellem esse gravis nec eum $\mathrm{ab}$ oculis tuis avellere. Itaque abs te per amicitiam nostram peto me libere de tua voluntate certiorem ut facias. Nam si tibi statum est convictores omnes dimittere, vitam ut agas quietiorem, non repugno; at si non grave perstare in eo purgatorio, optarim non excludi Guilielmum, sed ut tota hieme proxima et ventura Lipsium habeat praeceptorem, ne dicam numen: quod ego et Galliae et Italiae et Romae, imo et toti terrarum orbi, antepono. Tu tamen impera, ego parebo." Zitiert nach Peeters 1999, 146 f., Anm. 22.

9 Das Datum der Abreise lässt sich aus einem auf den 16. September 1601 datierten Gedicht rekonstruieren, das Justus Lipsius den beiden Schülern mit auf den Weg gab und das von Philipp Rubens 1608, 97, veröffentlicht wurde. Deutlich bezeugt auch dieses Gedicht, dass die von Warnke 1965, 24, geäußerte These einer Abwendung der Schüler von Lipsius nicht haltbar ist. Dazu auch Heinen 2009. 
mit anderen Schülern und Freunden des Justus Lipsius. ${ }^{10}$ Der damals schon weltberühmte Philosoph hatte seine Schützlinge vermutlich mit einem Empfehlungsschreiben ausgestattet, das ihnen alle Türen öffnete. ${ }^{11}$ Zudem ließ Lipsius in jenen Jahren keine Gelegenheit aus, seinen römischen Korrespondenten und jenen Briefpartnern gegenüber, die Kontakte nach Rom unterhielten, die besonderen Vorzüge von Philipp Rubens und Guillaume Richardot aufzuzählen. ${ }^{12}$ Nicht zuletzt durch diese Empfehlungen waren die beiden Niederländer in Rom fest in das Netzwerk der europäischen Communitas litteraria integriert. ${ }^{13}$ Dabei versteht es sich, dass die weitgespannten Kontakte Philipps, der am 13. Juni 1603 in Rom den Grad eines Doktors beider Rechte erwerben sollte, auch Peter Paul Rubens in mehr als einer Hinsicht zustatten kamen. ${ }^{14}$ Er konnte nämlich nicht nur intellektuell von den Beziehungen seines Bruders profitieren, sie waren auch seiner Karriere als Maler zuträglich.

Die familiären Beziehungen kamen erstmals voll zum Tragen, als Erzherzog Albrecht eine Serie von Altarbildern für die Kapelle der heiligen Helena in der berühmten Kirche Santa Croce in Gerusalemme in Rom zu stiften wünschte. ${ }^{15}$ Schon einige Jahre zuvor hatte der Erzherzog dieser Kirche eine kostbare Reliquie verehrt, einen Splitter vom wahren Kreuz Christi. Diese Reliquie war allerdings gestohlen worden und nun wünschte der Erzherzog baldmöglichst Ersatz, um wieder durch eine bedeutende Stiftung in dieser Kirche vertreten zu sein. Sein großes Engagement lag in der Tatsache begründet, dass er den Kardinalshut, den er als Erzbischof von Toledo bis zu seiner Hochzeit getragen hatte, in eben dieser Kirche empfangen hatte. Um einen geeigneten Maler für die Ausgestaltung des Altares zu finden, schrieb Albrecht am 8. Juni 1601 an seinen Vertreter in Rom, an den Gesandten Jean Richardot. ${ }^{16}$ Jean war der Sohn des gleichnamigen

10 Huemer 1985, $123 \mathrm{f}$.

11 Dieses Schreiben hat sich meines Wissens nicht erhalten. Wie man sich allerdings ein solches testimonium vorzustellen hat, verrät ein Schreiben, das Lipsius 1603 für G. Rivio ausstellte. Lipsius 1675, Bd. 2 (Ep. cent. V, 62), 494.

12 Vgl. Lipsius 1675, Bd. 2, 309 (Ep. cent. III, 86); ebd., Bd. 2, 468 (Ep. cent. V, 33); ebd., Bd. 2, 480 (Ep: cent. V, 46); ebd., Bd. 2, 495 f. (Ep. cent. V, 64); ebd., Bd. 2, $501 \mathrm{f}$. (Ep. cent. V, 70).

13 Zur Integration der Brüder Rubens in dieses Netzwerk vgl. auch Jaffé 1977, bes. 5-7.

14 Zur Promotion von Philipp Rubens vgl. Dok. vom 13. Juni 1603. Vgl. Génard 1877, 353-357.

15 De Maeyer 1955, 94 f.; Brown 1998, 121-128.

16 „Le Président, votre père, nous a communiqué ce que luy avez escrit et du debuxo (qu'attendons par Vencislaus van Obbergen) du reliquiario, et des voix que faictes 
Vorsitzenden des Geheimen Rates der habsburgischen Niederlande und der älteste Bruder eben jenes Guillaume, der gerade mit Philipp Rubens durch Italien reiste. So war denn der Maler schnell gefunden, der dem Legaten geeignet schien, ein Altarbild für die Kapelle der heiligen Helena zu schaffen. War zuerst nur von einem Gemälde für den Hochaltar die Rede gewesen, wurde dieser Auftrag schon wenige Monate später um zwei weitere Werke erweitert, die die Seitenwände der Kapelle schmücken sollten. Sie werden erstmals in einem Brief erwähnt, den Jean Richardot am 26. Januar 1602 an Vincenzo Gonzaga sandte, um eine Verlängerung von Rubens' Romaufenthalt zu erwirken. ${ }^{17}$ Dem Bemühen war Erfolg beschieden, und so konnte Rubens die Gemälde zur vollsten Zufriedenheit seiner Gönner vollenden. ${ }^{18}$ Mit seiner Heiligen Helena bei der Auffindung

chercher, et va bien tout ce que luy en dictes. Et quant à la table d'autel pour la Chapelle de Ste. Hélène, nous nous contentons que vous la faictes faire en telle forme que par delà entendrez sera la meilleure, puisque vous dictes qu'elle ne coustera que cent ou deux cens escus. Que quand nous sçauros le pris, tant de cela que des debuxo et Reliquiario, nous vous ferons remettre par delà tout ce qu'en aurez desbourssé." Rooses/Ruelens 1887-1909, Bd. 1, 21, Nr. 3; De Maeyer 1955, 94 f., hat zu Recht darauf hingewiesen, dass der Erzherzog sehr genau über die Wahl des Malers unterrichtet war und Richardot wohl kaum alleine entschieden haben dürfte.

17 „Ser ${ }^{\mathrm{mo}}$ Signore. Se bene sara importunita la mia di fastidire a V. A. con questa lettera, nientedimeno io spero mi darà licenza che gli faccia intendere brevemente, come avendo ordine dal Arciduca Alberto, mio Sig $^{\text {re }}$, di restaurare una capella di $S^{\text {ta }}$ Melena nella chiesa $S^{\text {ta }}$ Croce in Hierusalem, che fu titolo di A. nel tempo del cardinalato, feci diligentia di ricercare un giovane pittore fiamengho Pietro Paulo, ch'ha nome d'esser valent'huomo nel l'arte sua, ser ${ }^{\text {re }}$ di V. A., et col beneplacito del $\mathrm{Sig}^{\mathrm{r}}$ Lelio Arrigoni, suo ambasciatore in questa corte, mi lasciò finito di mano sua un quadro grande per detta capella, il quale però deve essere accompagnato d'altri duo piccoli, o altrimente restarla del tutto l'opera imperfetta et priva dell'ornamento suo, ma essendo richiamato esso Pietro Paulo di V. A. non potria finirli senza licenza espressa sua, di che io ne prego humiliss ${ }^{\text {te }} \mathrm{V}$. A. come si possa pero fare senza ritardare il servitio suo, et credo bene che cosi poco tempo non pregiudicare niente alle grande et magnifiche opere che mi dice ha comminciato V. A. in Mantoa, et haverà anco parte in questa devozione dell'Arciduca, mio patrone, dove io pregarò et in ogni altro luogo, nostro $S^{\text {re }}$ Iddio concedi $\mathrm{a} V$. A. tutto il bene et prosperità che Lei desidera. Da Roma a di 26 Gennaro 1602. Di V. A. Ser ${ }^{\mathrm{ma}}, \mathrm{Hum}^{\mathrm{mo}}$ et $\operatorname{devot}^{\mathrm{mo}}$ $\mathrm{Ser}^{\mathrm{re}}$, Gio. Ricciardotto“. Rooses/Ruelens 1887-1909, Bd. 1, 43, Nr. 9.

18 Diesen Auftrag mit seinen komplexen bildtheologischen Implikationen hat Rubens nur auf der Grundlage eines eingehenden Verständnisses für derartige Fragen bearbeiten können. Heinen 1996, 215 f., Anm. 219, hat zu Recht darauf hingewiesen, dass die Kreuzesverehrung, um die es in diesen Bildern vor allem geht, ein um 1600 umstrittenes Thema war, an dem die Bilderfrage exemplarisch diskutiert wurde. Rubens' merkliches Bemühen um die historische Authentizität seiner 
des heiligen Kreuzes für den Hauptaltar und den beiden flankierenden Bildern, einer Dornenkrönung und einer Kreuzaufrichtung, vermochte sich Rubens innerhalb der römischen Kunstwelt zu positionieren. ${ }^{19}$

\section{2. „Ein mächtiger Wettstreit"}

Rubens' flämischer Landsmann Karel Van Mander hat 1604 in seinem Schilder-Boeck jene Konkurrenzsituation beschrieben, die damals in Rom herrschte. ${ }^{20}$ Mit dem Pontifikat von Clemens VIII. habe, angefacht von kirchlichen und weltlichen Würdenträgern, eine Art Wettbewerb begonnen, „alles zu tun, um Perfektion zu erreichen. Dann zeigt sich, dass ein mächtiger Wettstreit entbrennt, und ein Wettlauf zwischen ihnen. Hier wird ein flammender Eifer entfacht, dort beginnt die ausgezehrte Missgunst, im Verborgenen ihre schwarzen Schwingen zu regen, und alle tun ihr Bestes, um den ausgesetzten Siegespreis für sich einzustreichen. ${ }^{\text {"21 }} \mathrm{Be}$ sonders stark sei das Bemühen der anderen Künstler gewesen, Cavaliere d'Arpino zu übertreffen, den Lieblingsmaler des Papstes. Zwei Maler taten sich dabei, Van Mander folgend, besonders hervor, nämlich Annibale Carracci und Michelangelo Merisi da Caravaggio. ${ }^{22}$ Vor dem Hintergrund

Darstellung ist in diesem Zusammenhang zu sehen, wobei eine eingehende Untersuchung zu diesem Aspekt aber noch immer aussteht. Scavizzi 1989, bes. $41-$ 42.

19 Peter Paul Rubens: Dornenkrönung. Öl auf Holz, $224 \times 180 \mathrm{~cm}$. [Heute:] Grasse, Kathedrale. Vgl. Kat.-Ausst. Lille 2004, 35, Kat.-Nr. 8; Kat.-Ausst. Braunschweig 2004, 282 f., Kat.-Nr. 70. Zum Hauptbild: Vlieghe 1972, Bd. 2, 58-61.

20 „Doch d'Italianen, daer ick van voor hadde te verhalen, wanneer dat den Paus en de Princen onse Const toeghedaen zijn, en ghenuecht hebben Palleysen, Kercken, en anders te vercieren, en dat sy eenigh uytnemende Oeffenaer onser Consten, met rijcklijcke belooninghe, en gheschencken versien, en voorspoedelijck helpen tot eerlijcken staet, dan beginnen de geesten te wackeren, en d'ooghen opdoende, verder te sien, en allen vlijt te doen, om op te stijgen tot volcomenheyt." Die Schilderung findet sich in den "Leven Der Moderne, oft dees-tijtsche doorluchtighe Italiaensche Schilders" bei Van Mander 1604, fol. $190^{\mathrm{v}}-191^{\mathrm{r}}$.

21 „Dan ontstaetter om sien eenen genuechlijcke[n] strijdt, en een om snelst loopen tusschen dese: hier wert eenen brandenden ijver t'ontsteken: hier begint de magher afjonsticheyt in 't verborgen haer swarte wiecken te roeren, en elck zijn best te doen, het voorgestelde prijs-teycken nae hem te strijken." Van Mander 1604, fol. 190".

22 Van Mander 1604, fol. 190": „Dus isset oock toeghegaen te Room, onder de Const: want doe Iosepino om de deucht zijner Consten by den grooten dus werdt ghesien, in voorspoet en eeren opgetoghen, hebben veel hem ghesocht nae te volgen, ghelijck te zijn, oft voorby te loopen. Waer door eenighe wonderlijck 
dieser vielfach dokumentierten Konkurrenzsituation und dem sie begleitenden ästhetischen Diskurs muss Rubens' Auftrag gesehen werden. Durch die so geschickte wie anspielungsreiche Verarbeitung etlicher Bildmotive, die Rubens in zahlreichen Studien in der Zeit seines italienischen Aufenthaltes gesammelt hatte, gelang es ihm, sich innerhalb dieses ästhetischen Diskurses zu verorten. ${ }^{23}$ Wenn man zum Beispiel in Betracht zieht, dass Caravaggio in einem um 1605 entstandenen Gemälde auf Rubens' Dornenkrönung reagierte, dann ist dies wohl der beste Beweis dafür, welch gute Position sich Rubens innerhalb des römischen Konkurrentenfeldes erobert hatte. ${ }^{24}$ Ein Beleg für die große Wirkung, die Rubens' Bilder hatten, ist auch die Würdigung durch die zeitgenössische Kunstkritik. So findet zum Beispiel der römische Maler Giovanni Baglione, seit dem heiligen Jahr 1600 Mitglied der Accademia di San Luca, ausgesprochen lobende Worte für "den jungen Flamen“, dem er 1642 die Ehre einer ausführlichen Würdigung zuteil werden ließ. ${ }^{25}$ In seine Vitensammlung römischer Künstler integrierte er auch die Lebensbeschreibung jenes ,giouane Fiamingo", der unter dem Pontifikat Clemens VIII. in die Stadt gekommen

ghevordert, en in de Const toeghenomen hebben. Onder ander isser eenen geheeten Caratz, woonende tot den doorluchtighen Cardinael Farnees, alwaer hy verscheyden fraey dingen heeft ghedaen, [191'] die seer uytmuntende zijn, insonderheyt een schoon gallerije, die so uytnemende gheschildert is op t'nat, datter geseyt wort, dat dese maniere die van alle ander Meesters te boven gaet, en dat de schoonheyt niet uyt te spreken is. Daer is oock eenen Michael Agnolo van Caravaggio, die te Room wonderlijcke dinghen doet: [...] Desen Michael Agnolo dan heeft alree met zijn wercken groot gherucht, eere, en naem gecreghen." Zu diesem künstlerischen Wettstreit ausführlich Brown 2001, 250-273. Hier auch der Hinweis auf den Text Van Manders, der allerdings in einer beinahe sinnentstellenden Übersetzung zitiert wird.

23 Die zahlreichen in den Bildern ablesbaren Entlehnungen, die vom Zitat des Belvedere-Torsos über weitere Antikenallusionen bis zu Anspielungen auf Werke Raffaels, Tizians und Reaktionen auf die zeitgenössische römische Malerei reichen, sind vielfach benannt worden, so beispielsweise von Rooses 1903, 63-65; Evers 1942, 40-42, sowie ausführlich von Müller Hofstede 1977 und Jaffé 1977. Zu den Antikenzeichnungen liegen als gründliche Studien die Arbeiten von Van der Meulen 1994-1995 und Westfehling 2001 vor.

24 Michelangelo Merisi da Caravaggio: Dornenkrönung. Öl auf Leinwand, $178 \times$ $125 \mathrm{~cm}$. Prato, Cari Prato, Cassa di Risparmio di Prato SpA. Vgl. dazu Brown 2001, 258 f., Nr. 97. Die Zuschreibung wurde zwar verschiedentlich bestritten, doch besteht weitgehend Einigkeit, dass in diesem Gemälde in jedem Falle die Komposition Caravaggios überliefert ist. Die Auseinandersetzung Caravaggios mit Rubens' früher Komposition steht demnach außer Frage. Zur Zuschreibungsdiskussion vgl. Brown 2001, 273, Anm. 48 und 49.

25 Baglione 1642, 362-364. Zu Bagliones Vite vgl. Schlosser 1924, $411 \mathrm{f}$. 
sei. Dieser Peter Paul Rubens habe sich einer durchaus italienisch anmutenden Art des Malens befleißigt, - „vna maniera buona Italiana“ ${ }^{26}$ Explizit erwähnt Baglione auch die "geschmackvollen" Werke in der Kapelle der heiligen Helena, die er als „con amore fatta“ charakterisiert, als „mit Liebe gemalt“ ${ }^{27}$ Ausführlich beschreibt er alle drei Bilder, wobei nur die Dornenkrönung etwas zu kurz kommt. Sie erinnerte Baglione wohl allzu stark an die malerische Faktur Caravaggios, gegen den er eine tiefe persönliche Abneigung hegte. ${ }^{28}$ Eine vergleichbare Zwistigkeit bestand wohl auch mit Giovanni Pietro Bellori, der später behauptete, der gänzlich kunstfremde Schriftsteller Ottavio Tronsarelli habe für den völlig illiteraten Baglione die Vitensammlung verfasst. ${ }^{29}$ Seine Aversion gegen Baglione hinderte Bellori allerdings nicht, sich dessen positivem Urteil über Rubens anzuschließen und die Gemälde in der vom Erzherzog gestifteten Kapelle ob ihres eindringlichen Naturalismus ausdrücklich zu loben. ${ }^{30}$ Damit war

26 Baglione 1642, 362: „Nel Pontificato di Clemente VIII. venne in Roma vn giouane Fiamingo, che Pietro Paolo Rubens nominauasi, il quale era stato per alcun tempo in Mantoua al seruigio di quell'Altezza, \& iui fece diuerse opere, \& in particolare dipinseui alcuni ritratti assai belli. Venne egli in questa Reggia del Mondo, per dar perfettione alla sua virtù, e vedendo, e studiando l'esquisite opere della mirabil Roma sì antiche, come moderne, apprese egli buô gusto, e diede in vna maniera buona Italiana."

27 Baglione 1642, 362: „Gli fu dato a dipingere nella Chiesa di Croce in Gerusalemme, giù, dentro la Cappella di Elena, Madre del Gran Costantino Imperadore, che dal Cardinal'Arciduca Alberto d'Austria era stata risarcita, e nel principale altare vi rappresentò Elena, che abbraccia la Croce del Redentore in atto assai deuota con diuersi puttini, che d'intorno scherzano, $\&$ ha prospettiua, opera a olio con amore fatta. Sopra vn'altare a man diritta v'ha figurato, quando Giesù fu incoronato di spine con diuerse figure intorno di colorito molto oscuro; e di notte finto. E nell'altro a man manca v'ha la Crucifissione del N. Saluadore con diuersi manigoldi, che fanne atto di voler'alzare la Croce, molto buone figure, come anche il Christo, e sonui le Marie con N. Donna isuenuta, assai gratiose, tutte a olio formate con forza, e con buon gusto."

28 Baglione verdächtigte Caravaggio, ein Spottgedicht auf ihn verfasst zu haben und ließ ihn deshalb 1603 vor Gericht stellen. Diese gerichtliche Auseinandersetzung hatte den Bruch zwischen beiden Künstlern zur Folge. O’Neil 1996, mit weiterführender Literatur.

29 Schlosser 1924, 412.

30 Bellori 1672, 222: „Dopò si condusse à Roma, nel qual tempo rimanendo à farsi li quadri ad olio nella Chiesa di Santa Croce in Gerusalemme, entro la Cappella di Santa Helena ristaurata dal Cardinale Arciduca Alberto d'Austria titolare di quella Chiesa, furono dati à dipingere al Rubens la Santa con la Croce nell'altare di mezzo, e nelli due laterali la Coronatione di spine, e la Crocifissione del Signore, nelle quali opere egli si mostrò pratico nel colorire dal naturale." 
es Rubens gelungen, sich mit den Gemälden in Santa Croce in Gerusalemme innerhalb der römischen Kunstszene zu etablieren. Doch hatte dieser Auftrag einen noch weiter reichenden Nutzen, denn er hatte damit zugleich ein bedeutendes Werk für seinen niederländischen Landesherrn geschaffen. So vermochte er sich mit diesen drei Bildern nicht nur in der Fremde zu positionieren, sondern sich zugleich auch noch in der Heimat einen Namen zu machen.

Bei ihrer Beurteilung von Rubens' Leistungen sind sich Baglione und Bellori völlig darin einig, dass er ein besonderes Geschick im Umgang mit den Großen und Mächtigen besessen habe. ${ }^{31}$ Diese besondere Gabe kam ihm auch zustatten, als es ihm wenige Jahre später gelang, den einflussreichen Kardinal Cesare Baronio zu beeindrucken. Auch um mit diesem gebildeten Philologen in Kontakt zu treten, mag dem Maler der in römischen Humanistenkreisen etablierte Jean Richardot behilflich gewesen sein. ${ }^{32}$ Doch könnte der Kontakt zu Baronio auch auf andere Weise zustande gekommen sein, denn dieser unterhielt eine rege Beziehung zu einigen der niederländischen Humanisten, mit denen Rubens in der Zeit seines römischen Aufenthaltes verkehrte. ${ }^{33}$ In jedem Falle hatte Rubens es Baronio zu danken, dass er den Zuschlag für einen der bedeutendsten Aufträge erhielt, der damals in der ewigen Stadt zu vergeben war.

Nachdem Rubens noch im Jahre 1602 nach Mantua zurückgekehrt war, hatte ihn der Herzog mit Geschenken für König Philipp III. nach Spanien gesandt. ${ }^{34}$ Im Anschluss daran war Rubens über Genua nach

31 „Pietro Paolo Rubens fu dotato, non solo della virtù della Pittura, ma hebbe anche accompagnate maniere bellissime di trattar negotij, massimame[n]te di gran portata." Baglione 1642,363 . „E se bene in questi moderni secoli non è mancato à nostri Artefici l'industria, e la gloria dell'opere loro, che ancora arrecano stupore; e la pittura si mantiene l'honorato nome dell'arti ingenue nella somma estimatione de' Principi, e delle nationi, contuttociò venendo essa trattata da molti, che non impiegano l'animo, ma solo la mano alla pratica, \& ad vn sordido guadagno; per lo disprezzo di costoro, diuiene ella mecanica, e vile nell opinione delle genti, con pregiuditio de' nobili ingegni che si affaticano di perpetuare in essa il nome loro." Bellori 1672, $221 \mathrm{f}$.

32 Ausführlich zu Rubens' Auftrag für die Chiesa Nova vgl. von zur Mühlen 1990, bes. $31-44$.

33 Man mag auch spekulieren, dass der Einfluss des mit Justus Lipsius befreundeten Kardinals Bartolomeo Cesi hier wirksam wurde, für den der Rubens nahestehende Jan Hemelaer als Bibliothekar arbeitete. Genauso mag auch Scipione Borghese für Rubens gesprochen haben. $\mathrm{Zu}$ den vielfältigen Beziehungen all dieser Personen auch Müller Hofstede 1966.

34 Vgl. dazu Büttner 2006, 64-68. 
Mantua zurückgereist, wo er zu Beginn des Jahres 1604 mit der Arbeit an drei gewaltigen Gemälden für die Jesuitenkirche begonnen hatte. ${ }^{35} \mathrm{Als}$ er diese im Sommer 1605 vollendet hatte, kehrte Rubens gegen Ende des Jahres nach Rom zurück. Sein Bruder Philipp war inzwischen nicht nur promoviert worden, sondern zudem zum Bibliothekar des Kardinals Ascanio Colonna avanciert. Die Brüder lebten nun gemeinsam in einem Haus nah der Piazza di Spagna und verkehrten in einem intellektuell regen Freundeskreis, der vor allem aus Tedeschi bestand, aus Deutschen und Niederländern. ${ }^{36}$ Der deutsche Arzt Johann Faber zählte genauso dazu wie der Philologe Gaspar Schoppe, der Lipsius-Schüler Jan Hemelaer und zahlreiche Künstler, darunter Adam Elsheimer und Paul Bril. ${ }^{37}$ Man mag es fast wörtlich nehmen, wenn Rubens zu Beginn des Jahres 1609 in einem aus Antwerpen an Johann Faber gerichteten Brief zum Ausdruck bringt, wie sehr er diesen Freundeskreis vermisst: „Ich bitte Sie, mich Herrn Schoppe zu empfehlen, wenn er nach Rom zurückkehrt, und auch meinem Kollegen Adam, Herrn Enrico und anderen guten Freunden, deren interessanter Verkehr mich noch oft Rom nachtrauern lassen wird." ${ }^{\text {"38 }}$

35 Kat.-Ausst. Köln 1977, 100-105 (Müller Hofstede). Vom Aufenthalt in Genua zeugen einige hervorragende Bildnisse. Vgl. dazu Kat.-Ausst. Lille 2004, 27, 4346, Kat.-Nrn. 14 und 15.

36 Diesem römischen Freundeskreis hat Huemer 1996 eine umfangreiche Untersuchung gewidmet. Für neuere Literatur vgl. Heinen 2001, 70-109, bes. $74 \mathrm{f}$, der richtig konstatiert, dass die in der stoischen Ethik begründete Standfestigkeit und geduldige Beharrlichkeit in der zutiefst christlich motivierten Naturforschung jener Zeit in einen schon von Lipsius gepflegten, auf die Sache konzentrierenden Freundschaftskult eingebettet war. $\mathrm{Zu}$ den vielfältigen Aktivitäten vgl. Huemer 1996, 3-27. Zu dem Freundschaftskült rund um Lipsius vgl. Morford 1991 sowie die leider bislang unpublizierte Arbeit von Bomford 2000.

$37 \mathrm{Zu}$ dem Arzt und Anatomen Johann Faber, der das ehrenvolle Amt des Conservators der päpstlichen Gärten innehatte, vgl. Heinen 2001, 79, 83, 91 f. Gaspar Schoppe stand nach seiner Konversion zum Katholizismus seit 1597 in Rom im Dienst der Päpste Clemens VIII. und Paul V. Wegen seiner spitzen Feder berüchtigt, sah er sich mehrfach polemischen Angriffen ausgesetzt, die bis zum Pornographieverdacht reichten. Vgl. Grafton 1983, Bd. 2, 246-250; Neumeister 1998, 380-390. Zu Jan Hemelaer vgl. Huemer 1985, 123 f. Dass Schoppe in Rom mit den Brüdern Rubens „familiarissime“ verkehrte, bestätigt Grubinus $1611,147$.

38 Zoff 1918, 73, Nr. 20. Rooses/Ruelens 1887-1909, Bd. 6, 324, Nr. 933: „Supplico V. al arivo [sic] del Sigr. Scioppio in Roma a voler me li tener in Gratia e quella del Sig. Adamo mio compare, il Sigr. Enrico et altri boni amici la cui bona conversatione mi fara venire talvolta martello di Roma." 
3. „con tanta gloria contra le pretensioni di tutti li primi pittori“

Zum intellektuellen Umfeld der Brüder Rubens und ihres Freundeskreises gehörten auch die Angehörigen der 1603 durch Federico Cesi gegründeten Accademia dei Lincei, der 'Akademie der Luchse'. ${ }^{39}$ Diese erste naturwissenschaftliche Gesellschaft wiederum, der 1611 nach langjährigen Kontakten sogar Galileo Galilei beitrat, war auf das Engste mit den Patronagenetzwerken des päpstlichen Rom verflochten. ${ }^{40} \mathrm{Zu}$ den Förderern und Kontaktleuten zählte neben vielen anderen auch der vielseitig gebildete Cesare Baronio, der heute als ein Begründer der christlichen Archäologie gilt. ${ }^{41}$ Er war der Spiritus Rector jenes großen Auftrages, der Rubens endgültig bekannt machen sollte. Immer noch als Maler dem Mantuaner Hof verbunden, berichtete Rubens am 2. Dezember 1606 an Annibale Chieppio, dass er leider nicht so bald zurückkehren könne.

Da sich mir nun die schönste und prächtigste Gelegenheit von ganz Rom bot, so trieb mich auch mein Ehrbestreben an, mir diesen günstigen Zufall zunutze zu machen. Es handelt sich um den Hauptaltar der Chiesa Nuova der Priester des Oratoriums von Santa Maria in Vallicella, ohne Zweifel heutigen Tages die meist gefeierte und besuchteste Kirche Roms, da sie gerade im Mittelpunkt der Stadt gelegen ist und durch den Wettbewerb der tüchtigsten Maler Italiens ausgeschmückt worden ist, so dass jetzt schon, da das besagte Werk noch gar nicht angefangen wurde, angesehene Persönlichkeiten sich dafür interessiert haben. Es würde meiner Ehre zu großem Nachteil gereichen, wenn ich diesen Auftrag ausschlüge, den ich ruhmvoll trotz des Wettbewerbes der ersten Maler Roms erhalten habe, und ich würde meinen Gönnern damit ein großes Unrecht zufügen und sie beleidigen, denn ließe ich durchscheinen, dass meine Verpflichtungen in Mantua meine Dienstfertigkeit beeinträchtigen, so würden sie in diesem Falle anerbieten, sich beim Herzog für mich zu verwenden, indem sie Seiner durchlauchtigsten Hoheit versicherten, dass es ihm äußerst lieb sein müsse, dass einer seiner Diener ihm in Rom solche Ehre mache. Ich weiß auch, dass Kardinal Borghese es daran nicht fehlen ließe, sich zu meinen Gunsten zu verwenden. ${ }^{42}$

39 Huemer 1996, XVI-XIX, 3-27.

40 Der Hinweis auf dieses komplexe Netzwerk bei Heinen 2001, 74 f. Zum Kontakt der Akademie zu Galileo vgl. Huemer 1996, XVII, 6; zum Beitritt Galileos vgl. Baudouin 1995, 81.

41 Biagioli 1999, 312-317. Huemer 1996, XVII, 4 und 6, nennt als Förderer und Kontaktleute u.a. die am päpstlichen Hof maßgeblichen Kardinäle Bellarmin, Baronius, Madruzzi, Olivier, Aldobrandi und Dietrichstein.

42 Die Übersetzung in Anlehnung an Zoff 1918, 61, Nr. 14. Rooses/Ruelens 1887 1909, Bd. 1, 354, Nr. 89: „Offerendosi dunque la più bella et superba occasione di tutta Roma mi spinse ancora zelo d'honore a prevalermi della mia sorte. Quest'è l'altar magg ${ }^{\text {re }}$ de la Chiesa nuova delli Preti dell'Oratorio detta Maria in Valicella, 
Ganz ausdrücklich betont Rubens in diesem Brief sein Ehrbestreben, den "zelo d'honore". Dieses durchaus nicht anrüchige Bekenntnis war durch Ciceros Diktum legitimiert, „dass man auf Erden nach nichts ernstlich streben darf als nach wahrem Ruhm und Ehrenhaftigkeit“. ${ }^{43}$ Noch verstärkt wird diese Aussage, wenn Rubens bekennt, dass es mit seiner Ehre, also "con honore" unvereinbar wäre, wenn er diesen Auftrag ausschlüge, den er im ruhmvollen Wettstreit gegen die besten Maler Roms errungen habe - „con tanta gloria contra le pretensioni di tutti li primi pittori di Roma“. Dabei verstand es sich für Rubens, dass der von ihm erworbene Ruhm auch seinem Fürsten nutze, indem sein Diener einen von angesehenen Persönlichkeiten viel beachteten und bedeutenden Auftrag in Rom ausführe, „ch'un suo servitor li faccia tal honor in Roma“. Ruhm und Ehre sind die zentralen Begriffe dieses Schreibens, das aber auch in anderer Hinsicht aufschlussreich ist. In aller Offenheit bekennt Rubens nämlich, dass er diesen Erfolg einigen Gönnern verdanke, die er nun unmöglich enttäuschen könne, "miei fantori che resteriano disgustatissimi“. Diese ungenannten Gönner brauchte Rubens nicht zu enttäuschen und auch die Intervention des Kardinals Borghese scheint sich erübrigt zu haben. Der Fürst bewilligte „seinem Maler“, wie er Rubens zu nennen pflegte, die drei Monate. „Ihr könnt ihn im übrigen wissen lassen“, schrieb Vincenzo an seinen römischen Agenten, Annibale Chieppio, „daß er mit diesen drei Monaten machen kann, was er will. “44

senza dubbio hoggidi la più celebrate et frequentata chiesa di Roma per essere situata giusto nel centro d'essa et adornata a concorrenza di tutti li più valenti pittori d'Italia, di maniera che ancora che dette opera non fosse comminciata ci sono interessati personaggi di tal qualità ch'io non potrei con honore lasciar un impressa ottenuta con tanta gloria contra le pretensioni di tutti li primi pittori di Roma, et farei grandiss ${ }^{\circ}$ torto alli miei fantori che resteriano disgustatissimi, perche movendo io qualche dubbio intorno la mia servitù di Mantova essi s'offersero in tal caso di intercedere per me apresso il Sig ${ }^{r}$ Duca, protestando a A. ${ }^{\text {za }}$ dover essere carissimo ch'un suo servitor li faccia tal honor in Roma, tra li altri il Sig ${ }^{r}$ Cardinal Borghese so che non mancarebbe d'adoperarsi in favor mio."

43 Cic. Arch. 14: „Nam nisi multorum praeceptis multisque litteris mihi ab adulescentia suasissem nihil esse in vita magno opere expetendum nisi laudem atque honestatem." Die Übersetzung zitiert nach Schönberger 1990, 21.

44 Die beinahe abschätzigen Zeilen entstammen dem Bewilligungsschreiben, das der Herzog am 13. Dezember 1606 an Chieppio sandte: „A Pietro-Paolo ci contentiamo di dar il termine di tre mesi, che desidera da starsene a Roma per compiere l'opera che ha alle mani, gli potrete pertanto far sapere che se ne stia a suo comodo per questi tre mesi, ma che per Pasqua di Resuretione infalibilte egli se ne venga a Mantova, che per quello tempo ci contentiamo che vi sia, affinche conosca che vogliamo compiacerlo, più tosto di più che di manco di quella che egli desidera." 
Rubens machte sich ans Werk und schuf nach zahlreichen Vorstudien, die er den Patres vorgelegt hatte, ein erstes großes Gemälde, das jedoch von den Verantwortlichen abgelehnt wurde. ${ }^{45}$ Der Maler selbst schob die Ablehnung dieses Bildes auf die komplizierte Lichtsituation, die zur Folge gehabt hätte, dass man das Bild nicht richtig habe betrachten können. ${ }^{46}$ Auch wenn diese geschickte Ausrede später von Bellori verbreitet wurde, war der Grund für die Zurückweisung doch tatsächlich ein anderer. Nach dem Tod des für die Auftragsvergabe und das ursprüngliche Bildkonzept maßgeblichen Kardinals Cesare Baronio hatte sich offensichtlich die Einstellung der kirchlichen Auftraggeber zum Medium Bild so grundlegend gewandelt, dass sie eine völlige Neuplanung für nötig hielten. ${ }^{47}$ In Santa Maria Nuova wurde nämlich ein wundertätiges Gnadenbild der Muttergottes verehrt und das galt es, in den Altar zu integrieren. In der ersten Fassung war dieses Bild nur in der gemalten Komposition angedeutet, doch war dies wohl nicht genug, und so erscheint in der zweiten Fassung das wundertätige Fresko tatsächlich als Einsatzbild in seinem materiellen Bestand. ${ }^{48}$ So gliederte Rubens bei dem endgültig ausgeführten

Rooses/Ruelens 1887-1909, Bd. 1, 357, Nr. 90. Der Wortlaut macht deutlich, wie wenig es dem Herzog darum zu tun war, dass "sein Diener" sich anschickte, durch die Tätigkeit in Rom mittelbar auch den Ruhm des Hauses Gonzaga zu mehren. Vielmehr kam es dem Mantuaner Herzog augenscheinlich gut zupass, dass er in einer finanziell angespannten Situation seinen Maler nicht unterhalten musste. Vgl. von zur Mühlen 1990, 23 f.

45 Peter Paul Rubens: Papst Gregor I. Öl auf Leinwand, $477 \times 288 \mathrm{~cm}$. Grenoble, Musée de Peinture et de Sculpture, Inv.-Nr. 97. Vgl. Kat.-Ausst. Lille 2004, 27, Abb. 3.

46 Diese Erklärung findet sich am 2. Februar 1608 in einem Brief an Chieppio: „Ha però sortito così sciagurata luce sopra quel Altare, che à pena si ponno discernere le figure non che godere l'esquisitezsa del colorito e delicatezza delle teste e panni cavati con gran studio del naturale i secondo il giudizio d'ognungo ottimamente rusciti." Rooses/Ruelens 1887 -1909, Bd. 1, 403, Nr. 108.

47 Von zur Mühlen 1990, bes. 44 und 49, hat die bildtheoretischen Implikationen der beiden Fassungen differenziert analysiert und deren Relevanz historisch einleuchtend verankert. Zum Streit um das nachtridentinische Sakralbild, in dessen Kontext auch diese Diskussion steht, grundlegend Heinen 1996, 25-29.

48 Vgl. von zur Mühlen 1990, 44-49. Nach dem Tridentinum galten, wie Heinen 1996, 24, betont, „nicht einer durch das Bild vermittelten Vision, in der die Heilige etwa anwesend wäre, sondern dem als vom Himmel herabgetragen dargestellten Gnadenbild selber, [...] die im Bild dargestellten Ehrungen. Auf das dahinter befindliche und nur zeitweise aufgedeckte, als Reliquie verstandene Gnadenbild verweist das von Rubens in seine Komposition integrierte Deckenbild. Das Bemühen, durch diese Präsentationsweise die Anbetung im tridentinischen Sinn auf den göttlichen Ursprung des Bildes zu verweisen, ist erkennbar, wenngleich die 
Werk die Komposition in drei getrennte, doch räumlich miteinander verbundene Gemälde, von denen er das eigentliche Altarbild betenden Engeln und einer Gloriole aus Cherubim vorbehielt, die das wundertätige Madonnenbild hielten, das in eine Aussparung im Original eingesetzt wurde. ${ }^{49}$ Diese zweite Fassung fand die ausdrückliche Zustimmung des Konvents und wurde von der römischen Kunstkritik gebührend gelobt. Es ließe sich hier noch viel zu den aemulativen Konkurrenzsituationen sagen, innerhalb derer Rubens sich im Verlauf seiner Karriere positioniert hat.

\section{4. aemulatio bei Franciscus Junius}

Rubens ist auch danach immer wieder mit anderen Künstlern in den Wettstreit getreten. Zahlreiche Beispiele für Konkurrenzsituationen und konkurrierende Bilder lassen sich anführen. ${ }^{50}$ Aber man kann in seinem Fall nicht allein den Wettstreit unter den konkreten Bedingungen der Kunstproduktion exemplarisch darstellen, sondern auch die theoretische Fundierung seines Begriffes von aemulatio. Rubens war ausgesprochen gebildet und verfügte über eine umfangreiche Bibliothek, in der sich auch zahlreiche kunsttheoretische Werke fanden. ${ }^{51}$ Bis heute hat sich beispielsweise ein Exemplar von Karel Van Manders Schilder-Boeck erhalten, auf dessen Titelblatt in wässriger Tinte „Ex libris Pet. $\mathrm{Pa}^{\circ}$ Rubens “ $z$ lesen ist. $^{52}$ Rubens mag also durchaus mit Van Manders zahlreichen Schilde-

Komplexität der bildlichen Argumentation Fehlverständnisse geradezu provoziert."

49 Peter Paul Rubens: Die Muttergottes von Engeln verehrt. Öl auf Schiefer, $425 \times$ $250 \mathrm{~cm}$. Rom, Santa Maria in Vallicella. Vgl. Kat.-Ausst. Lille 2004, 58, unter Kat.-Nr. 25; Kat.-Ausst. Wien 2004, 178-186, Kat.-Nrn. 17-20. Die Raumwirkung eines Altargemäldes durch zwei flankierende Bilder zu steigern, war ein Kunstgriff, den Caravaggio schon ein Jahr zuvor bei der Ausgestaltung der CerasiKapelle in Santa Maria del Popolo angewandt hatte. Zu diesen Arbeiten vgl. Brown 2001, 250-255.

50 Einen Einstieg in die vielfältigen Facetten des Themas eröffnet Kat.-Ausst. München 2009.

51 Arents 2001; Büttner 2002b.

52 Der Namenszug wurde sicher nicht von Rubens angebracht. Da jedoch im Katalog der Bibliothek von Albert Rubens ein Exemplar des Buches nachgewiesen ist, spricht nichts gegen die Annahme, dass es sich tatsächlich um das Exemplar aus Rubens' Bibliothek handelt. Vgl. Arents 2001, Nr. A1, 93-98; ebd. Anhang: Cat. Albert Rubens, 13, kol. 2; ebd., 351. Da das Schilder-Boeck nicht in den für Rubens' Bücherkäufe nach 1613 dokumentierten Rechnungen des Verlagshauses PlantinMoretus vorkommt, mag Rubens es schon früher angeschafft haben. Denkbar ist, 
rungen von Künstlerkonkurrenzen vertraut gewesen sein. ${ }^{53}$ Auch eine Ausgabe der Vitensammlung Vasaris nannte er sein Eigen, die ihm ausweislich einer Widmungsinschrift sein Freund Gaspar Gevaerts geschenkt hatte. ${ }^{54}$ Darüber hinaus besaß Rubens auch ein Exemplar der De pictura veterum libri tres des Franciscus Junius, dessen aemulatio-Konzept besonders im Kontext des kunsttheoretischen Schrifttums der klassizistischen Theoretiker im Umfeld der Pariser Akademie eine reiche Nachfolge fand. ${ }^{55}$ Trotz der breiten zeitgenössischen Rezeption, die ihn fraglos zu einem der meistgelesenen kunsttheoretischen Autoren des 17. Jahrhunderts werden ließ, wurde Junius von der kunsthistorischen Forschung bislang nicht selten übersehen. ${ }^{56}$ Das mag vor allem der Sperrigkeit seines Textes geschuldet sein, der aus unzähligen Klassikerzitaten besteht, die Junius zu einer Art Flickenteppich (cento) geordnet und mit verbindenden Zwischentexten zu einem geschlossenen Ganzen amalgamiert hatte. ${ }^{57}$ Der 1637 in Amsterdam publizierte Traktat verrät nicht allein die umfassende Kenntnis antiker Quellen zu Kunst und Künstlern, sondern auch die genaue Kenntnis der neueren kunsttheoretischen Literatur. ${ }^{58}$ Das Werk ist in

dass ihm sein Bruder Philipp bereits 1605 das frisch erschienene Werk mit nach Rom brachte, wie Heinen 1996, 193, Anm. 94, dies mit gutem Grund vermutet hat.

53 Vgl. Anm. 20.

54 Arents 2001, Nr. B3, $104 \mathrm{f}$. Das von Rubens mit handschriftlichen Notizen versehene Exemplar der Vite Vasaris in der Ausgabe von 1568 verschwand noch vor dem zweiten Weltkrieg aus der Bibliothek in Holker Hall. Dass Rubens mit Vasaris Terminologie vertraut war, belegt etwa eine Notiz auf der Federzeichnung mit dem Entwurf eines Orgelflügels von ca. 1612 im Cabinet des Dessins des Louvre oder eine Paraphrasierung von Vasaris Charakterisierung der offenen Malweise Tizians auf einer Zeichnung nach einem Fresko Pordenones. Vgl. Heinen 1996, 193, Anm. 94.

55 Junius 1637. Zur Rezeption in Frankreich vgl. Kayling 2003, 106; Nativel 2009.

56 „Von der Kunstgeschichte meist sträflich übersehen, gehört Junius zu den führenden Stimmen des 17. Jahrhunderts“, heißt es bei König/Schön 1996, 157. Es ist tatsächlich bezeichnend, dass Junius nur in diesem Band der auf fünf Teile angelegten Quellensammlung ausführlich zitiert wird. In den meisten Quellensammlungen findet er keine Erwähnung. Eine löbliche Ausnahme bildet neben dem genannten Werk Vöhringer 2010, 162-164.

$57 \mathrm{Zu}$ Junius und den De pictura veterum libri tres vgl. Schlosser $1924,559 \mathrm{f}$.; Ellenius 1960, 33-40, 48, 71-96; Emmens 1979-1981, Bd. 2, 58-59, 66-67; Nativel 1988; dies. 1989; dies. 1996; Warnke 1991; Aldrich/Fehl/Fehl 1991, Bd. 1, xiii-lxxxiii, bes. liii-lvi (Philipp P. Fehl); Heinen 1996, 201 f., Anm. 118-130.

58 Ellenius 1960, 73-90, hat nachgewiesen, dass Junius auf eine Reihe Kunsttheoretiker zurückgegriffen hat: Alberti, Ghiberti, Poliziano, Gauricus, Cardanus und 
drei Bücher gegliedert, die den Anfängen, den Fortschritten und der Vollendung der antiken Kunstübung gewidmet sind, denn anders als die eng gefasste Übersetzung des Titels „,von der Malerei“" vermuten lassen könnte, ist Junius' Abhandlung De pictura weit allgemeiner auf das Bildnerische bezogen. Jedes der drei Bücher beginnt mit einer knappen $\mathrm{Zu}$ sammenfassung der jeweiligen Zielrichtung, wobei im ersten Buch der Ursprung der Kunst erörtert wird. ${ }^{59}$ Hier werden Naturnachahmung und Phantasie, imitatio und phantasia, als maßgeblicher Antrieb der Kunstpraxis wie der Rezeption vorgestellt, denn um ein Kunstwerk richtig sehen und beurteilen zu können, müsse auch der Betrachter Einbildungskraft besitzen. Zugleich proklamierte Junius im ersten Buch seiner Abhandlung unter Verweis auf Simonides und andere klassische Autoritäten, dass Dichtung und Malerei als „Schwesterkünste“ anzusehen seien und mithin für beide die gleichen Regeln der Rhetorik zu gelten hätten. ${ }^{60}$ Ausgehend von dieser Grundannahme werden im zweiten Buch die Ausbildung des Künstlers und die Fortentwicklung der Kunst beschrieben. Zum zentralen Paradigma werden hier die Begriffe simplicitas und aemulatio. ${ }^{61}$ Den Begriff der simplicitas hat Junius der Stilkritik der antiken Kunstprosa entnommen. Bezogen auf die Bildsprache meint er damit deren Klarheit und eine gewisse Zurückhaltung in Formen und Farben sowie in der Komposition. ${ }^{62}$ Denn während der Dichter nach Verwunderung (admiratio) strebe, solle der Maler versuchen, jene Klarheit in der Stoffwahl und in der Ausführung

Demontiosius, aber vor allem beruft er sich auf antike Autoritäten wie Quintilian, Cicero, Tacitus, Plinius d.Ä., Plutarch und Pseudo-Longinus.

59 Ellenius 1960, 37.

60 Junius 1637, 23 (I, 3, 12). Für weitere Beispiele vgl. Schöne ${ }^{3} 1993,205$ f. Bis heute grundlegend: Lee 1967, bes. 3: „The saying attributed by Plutarch to Simonides that painting is mute poetry, poetry a speaking picture, was quoted frequently and with enthusiasm; and Horace's famous simile ut pictura poesis-as is painting so is poetry-which the writers on art expected one to read 'as is poetry so is painting', was invoked more and more as final sanction for a much closer relationship between the sister arts than Horace himself would probably have approved." Vgl. auch Pfisterer 1996, 109-118.

61 Die Tatsache, dass Junius' Buch schon 1641 in einer niederländischen Übersetzung erschien, erlaubt es, die zeitgenössische Bedeutung des Begriffs auch für die niederländische Sprache zu klären. Bei Junius 1641, 72, wird aemulatio als „eenen sekeren Naer-yver, ofte Æmulatie “ übersetzt, an anderer Stelle (96) als „volgh-lust“. Die simplicitas wird als „een slechteffene maniere van wercken“ wiedergegeben.

$62 \mathrm{Zu}$ der von Junius empfohlenen Zurückhaltung auch in der Darstellung von Bewegungen, die zur Verunklärung der Komposition und der Verteilung der Figuren im Bild führen könne, vgl. Ellenius 1960, 79, unter Verweis auf Quint. inst. VII. proemio 2. 
zu erlangen (evidentia), deren sich auch die großen Meister der Antike befleißigt hätten. ${ }^{63}$ Mit ihnen gelte es, in den Wettstreit zu treten, denn nichts reize den Kunstbeflissenen gleichermaßen an wie der Wettstreit und das Bessersein eines anderen, ,nihil eum æquè atque Æmulatio \& semper melior aliquis incitabat" ${ }^{64}$ Damit sind zunächst die Grundlagen für die höchste Blüte jeder Kunstübung benannt, denen der dritte Teil der Abhandlung gewidmet ist. In dessen Einleitung werden dann gleich die wichtigsten Grundsätze angeführt, die der Künstler zu beachten habe. Es seien von den Alten in der Malerei die Bilderfindung oder der historische Stoff zum Ausdruck gebracht worden, die Proportion oder Übereinstimmung aller Teile, die Farbgebung, und in ihr Licht und Schatten, Schmelz und Dunkel, die Bewegungen, und in ihnen Handlung und Gemütsbewegung und schließlich die Zusammenstellung oder die Ökonomie der Mittel, die die Anlage des Werkes als Ganzes betreffen. ${ }^{65}$ Den Schluss des Bandes bildet eine reiche Auswahl bildhafter literarischer Schilderungen, in denen vorbildliche Exempla bildwürdiger Gegenstände und ihre angemessenen Darstellungen vorgeführt werden. Im Zentrum dieser Überlegungen steht dabei der Grundsatz, dass Maler und Betrachter gleichermaßen gebildet zu sein hätten, da neben dem geübten Auge, der „oculorum

63 Junius 1637, 37 (III, 4, \$5): „præsertim cùm Poeticæ phantasiæ finis sit $\varepsilon \kappa \pi \lambda \eta \xi 1 \varsigma$

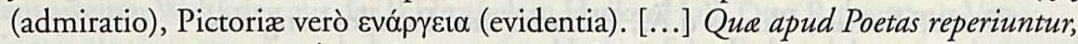
fabulosiores continent \& modum omne[m] fidemque superantes casus. At vero in pictoria phantasia prastantissimu $[\mathrm{m}]$ semper actionis possibilitas est, \& instita veritas. [...] Atque hinc etiam liquet, cur Dionys. Longinus phantasiæ finem faciat $\varepsilon v \alpha$ óp$\gamma \varepsilon ı \alpha$, sive evidentiam: cur itidem tantam tribuat phantasiae potentiam, ut afirmare ibidem non vereatur, orationem ejus, qui vim hanc imaginativam usu assiduo roboraverit, $[\ldots]$ non allicere modo, sed etiam subigere auditorem. "Junius zitiert hier Pseudo-Longinus 15, 8. Zu den Begriffen evóppeı $\alpha$ und evidentia vgl. Ellenius 1960, 76; Raupp 1984, 139; Heinen 1996, 186, Anm. 58.

64 Junius 1637, 50 (II, Arg.): ,sin autem recto ingenio preditus à prime institutionis integritate desciscere nefas habebat, nihil eum aquè atque Amulatio \& semper melior aliquis incitabat: quumque priores in prodigios à planè Simplicitate artis operibus suis commendationem ex vi potius artis, quàm exquisitis colorum pigmentis, soliti essent captare, ipse quoque in hoc amule artis certamine Simplicitatis hujus potissimam semper habebat rationem."

65 Junius 1637, 130 (III, Arg.): „Observabantur itaque ab antiquioribus in Picturâ quinque hæc capita: Inventio sive Historia: Proportio sive Symmetria: Color, \& in eo Lux \& Umbra, Candor, \& Tenebrae: Motus, \& in eo Actio \& Passio: Collocatio denique sive Oeconomica totius operis dispositio." Vgl. auch Ellenius 1960, 74. 
consuetudinem", vor allem das Studium der klassischen Schriften die Voraussetzung für ein begründetes Kunsturteil sei. ${ }^{66}$

Genau wie die Poesie gründet die Bildende Kunst - Junius folgend auf dem Prinzip der Nachahmung. ${ }^{67}$ Allerdings sei die Imitation der Natur und der großen Vorbilder stets der phantasia untergeordnet, jenes Inspirations- und Imaginationsvermögens, das der Künstler besitze. ${ }^{68}$ Doch auch die künstlerische phantasia wird dem getreuen Einhalten der überlieferten Regeln und dem genauen Studium der Vorbilder untergeordnet, deren Kenntnis von jedem Künstler zwingend zu fordern war. Inspiration war für Junius mithin nicht mehr als eine Metapher für den anspornenden und überwältigenden Eindruck, den der Künstler von den Meisterwerken der Vergangenheit empfangen sollte, um ihn zur aemulatio und damit zu

66 Junius 1637, 220 (III, 8, \$13): „Prætereundum tamen hîc non est, præter illam, quam Tullii verbis hactenus ursimus oculorum consuetudinem, aliam quoque nobis à Cassiodoruo præscribi viam, quâ pleniorem artium harum intelligentiam consequamur. etenim Variarum lib. VII, Formulâ 15, ad Præfectum urbis de Architecto faciendo, Romana fabrica decus, inquit, peritum convenit habere custodem; ut illa mirabilis sylva moenium diligentia subveniente servetur, \& moderna facies operis affabris dispositionibus construatur. Hoc enim studio largitas nostra non cedit, ut \& facta veterum exclusis defcetibus innovemus, \& nova vetustatis gloria vestiamus. Quapropter talia virum peritissimum suscipere decet; ne inter illa nimis ingeniosa priscorum, ipse videatur esse metallicus; \& intelligere non possit, que in illis artifex antiquitas ut sentirentur effecit. Et ideò det operam libris antiquorum; instructionibus vacet; ne quid ab illis sciat minus, in quorum locum cognoscitur surrogatus. vide

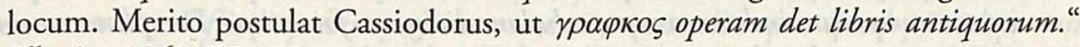

67 Ellenius 1960, 73-90.

68 Junius 1637, 37 (I, 4, \$5): „Quum itaque ex jam dictis perspicuum sit, phantasiam Poëtis atque Pictoribus magnificas imitandarum rerum species promtissimè suppeditare: nemini quoque dubium est, quin utriusque focundissima hæc imaginum parens sedulò sit fovenda atque excitanda: præsertim cùm: quod est omnium difficillimum, necesse sit opifici imaginem in animo permanere eandem semper, frequenter etiam multis annis, donec absolverit opus. Dio Chrysost. orat. XII, quæ est de Cognitione Die. Excitabitur autem \& roborabitur vis phantasix, si rebus magnis \& observatu dignis non leviter tantùm atque perfunctoriè oculos animumque intendant, sed mentes suas quotidianâ inspiciendarum formarum exercitatione vivis omnium rerum imaginibus usque adeò altè imbuant, ut memores visarum rerum species vel invitos sequantur." Junius gehörte zu den Ersten, die die Definition des Pseudo-Longinus „Über das Erhabene" und die Inspiration des Redners und Dichters (enthousiasmos) auf den bildenden Künstler übertrugen. Vgl. auch Junius 1637, 148 (III, 1, \$13). Im Unterschied zu den Schriften der italienischen Kunsttheoretiker fordert Junius nicht nur alle Qualifikationen des pictor doctus, sondern stellt zugleich besondere Anforderungen an die subjektive seelische Beschaffenheit der Künstlerpersönlichkeit, wie sie seit Aristoteles und dem PseudoLonginus nicht mehr formuliert worden sind. Vgl. dazu Raupp 1984, 140. 
eigenen großen Leistungen anzuspornen. ${ }^{69}$ Die durch Leon Battista Alberti als kunsttheoretischer Topos eingeführte aemulatio erhielt damit im Kontext der Kunsttheorie des Franciscus Junius einen zentralen Stellenwert, der durch eine ganze Reihe von Zitaten nach klassischen Autoritäten begründet und untermauert wird:

'Aber ich kann dennoch nicht umhin', sagt Velleius Paterculus (hist. I, 16 \& 17), 'von einer Sache etwas zu erwähnen, mit der ich mich schon oft beschäftigt habe, ohne zu einer Lösung gekommen zu sein. Man kann sich doch nicht genug darüber wundern, dass die größten Meister in jeder Kunst und Wissenschaft jeweils von der gleichen Art gemeinsam und in dem gleichen eng begrenzten Zeitraum auftreten [...]. Ich habe aber niemals etwas herausgefunden, was mir mit Sicherheit als die Wahrheit erschienen wäre, höchstens etwas, was der Wahrheit nahekommt. Und davon hat mich am meisten das Folgende überzeugt: Der Wetteifer nährt die Talente, und bald fordert Wetteifer, bald Neid zur Nachahmung heraus. Es liegt in der Natur der Dinge, dass alles, was mit höchstem Einsatz betrieben wird, auch zu höchster Vollendung kommt. [...] Es steht wirklich außer Frage, dass die Nachahmungsbegierde und der beständige Vorzug irgendeines anderen einst die Künstler beseelt habe. Allerdings darf man nicht glauben, dass die Kunst allein durch den gegenseitigen Wetteifer empor gebracht worden sei, sondern auch weil der Ruhm der beredtsten Leute ihrer Zeit dazu ermuntert habe, mit ähnlichen Werken in Wettstreit zu treten. ${ }^{.70}$

69 Junius 1637, 151 (III, I, \$15): „pereleganti similitudine testatum fecit Longinus, $\$ 11$. [...] Multi [inquit] alieno seu divino spirito afflati rapiuntur eodem prorsus modo, quo fama est Pythiam tripodi admotam corripi: ubi ut perbibent hiatus quidam est terre vaporum inde auramque exhalans divinam: factamque Deo plenam numinis instinctu, consulentibus responsa dare \& oracula reddere: sic ab illis priscorum magnis ingeniis in animos imitantium ipsos, tanquam ex sacris ostiis rivi quidam feruntur a quibus afflati etiam qui suapte natura non isto Phoebo aguntur furore, aliorum, magnitudine impulsi rapiuntur simul. Factum porro hoc non est censendum furtum, sed tanquam ab honestis \& preclaris moribus, aut figmentis efficta expressaque forma. Et revera praclarum hoc \& victoria dignissimum pro gloria certamen \& proelium: quippe in quo à majoribus vinci non sit inglorium. "Vielleicht war dieser Passus als eine gezielte Polemik gegen die Verteidigung der furores durch Francesco Patrizi gerichtet, bei dem sich schon die Idee findet, dass admiratio das Ziel der Dichtkunst sei. Vgl. Raupp 1984, 146, Anm. 476. Zu Junius' Einstellung zur Inspiration vgl. auch Emmens 1979-1981, Bd. 2, $109 \mathrm{f}$.

70 Junius 1637,67 (II, 5, \$2): „Vel. Paterculus lib. I hist. cap. 16, \& 17: Nequeo tamen temperare mihi, inquit, quin rem sapè agitatam animo, neque ad liquidum ratione perductam signem stilo. Quis enim abundè mirari potest, quod eminentissima cujusque professionis ingenia, in eandem formam \& in idem artati temporis congruant spatium, ¿ quemadmodum clausa capsà, alioque saepto, diversi generis animalia, nibilo minus, separata alienis, in unum quaque corpus congregantur; ita cuiusque clari operis capacia ingenia, in similitudinem \& temporum \& profectuum, semet ipsa ab aliis separaverunt? Hoc evenisse tragicis, comicis, philosophicis, historicis, grammaticis, plastis, 
Im Folgenden kommt Junius, auch unter Verweis auf die Historia Suevorum des Ulmer Mönches Felix Faber, zu dem Schluss, dass die Bildkünste blühten, als es auch die Eloquenz tat. ${ }^{71}$ Dies berührt eine andere Form der aemulatio als die zwischen Malern, nämlich den Paragone zwischen Literatur und Kunst. Die von der Rhetoriktheorie propagierte Zielsetzung der Humanisten, durch Nachruhm Unsterblichkeit zu erlangen, wird hier auch dem bildenden Künstler vor Augen gehalten. Und getreu dem Diktum Ciceros, dass die Ehre die Künste nährt, wird der künstlerische Wettstreit von Junius zur Grundlage jeder Weiterentwicklung der Künste erklärt. ${ }^{72}$

Gleichwohl wird der Künstler seine Seele noch höher erheben mit noch größerer Begeisterung sein Werk anfangen, wenn er außer dem notwendigen Wetteifer, den Apelles, Protogenes, Phidias, Polyklet gleichsam zu Begleitern seiner Unternehmung wählt, nicht etwa um bei sich zu erwägen, was diese Genies, sofern sie uns beim Malen anträfen, uns in diesem Fall raten würden, sondern zugleich, was sie von unseren vollendeten Arbeiten halten würden. Denn auch die Scham spornt zur gleichen Sorgfalt an, wie die Erwartung des

pictoribus, scalptoribus, ut quisque temporum institerit notis, reperiet, eminentia cuiusque operis artissimis temporum claustris circumdata. Huius ergò precedentisque seculi ingeniorum similitudines congregantis \& in studium par \& in emolumentum, causas cùm semper requiro, numquam reperio quas esse veras confidam, sed fortasse verisimiles, inter quas has maximè. Alit aemulatio ingenia, \& nunc invidia, nunc admiratio imitationem accendit; naturaque, quod summo studio petitum est, adscendit in summum difficilisque in perfecto mora est; naturaliterque, quod procedere non potest, recedit. '́, ut primo ad consequendos, quos priores ducimus, accendimur; ita, ubi aut prateriri aut aquari cos posse desperavimus, studium cum spe senescit, \& quod adsequi non potest, sequi desinit, \& velut occupatam relinquens materiam, querit novam; preteritoque eo in quo eminere non possumus, aliquid in quo nitamur, conquirimus, sequiturque ut frequens ac mobilis transitus, maximum perfecti operis impedimentum sit. $\$ 2$. Nullam profectò res hæc dubitationem habet, quin artifices ardor imitationis, semperque melios aliquis olim accenderit: sic tamen, ut non tantum mutua ad invicem æmulatione artem provectato esse censemus sed \& fecudissimorum sui sæculi virorum gloriâ magnos animos ad simile aliquid elaborandum æmulationis stimulis excitatos fuisse arbitremur." Dundas 2007, $55 \mathrm{f}$, hat darauf hingewiesen, dass Junius in seiner Ausgabe der Werke Sidneys ein Zitat von Velleius Paterculus (Historia 1, 17, 6) unterstrichen hat: „Alit aemulatio ingenia“ ('Der Wetteifer nährt die Talente'). Genau dieses Zitat begegnet auch in der Malerei der Alten.

71 Fabri 1605.

72 Cic. Tusc. I, 4: ,honos alit artes, omnesque incenduntur ad studia gloria, iacentque ea semper, quae apud quosque improbantur." ("Ehre nährt die Künste, und alle lassen sich zu den Künsten und Wissenschaften entflammen durch Ruhm, und dasjenige liegt stets darnieder, was keine Anerkennung findet.'). 
Lobes, indem das Verlangen zu gefallen jedes glückliche Bestreben auf das wunderbarste vermehrt. ${ }^{73}$

\section{Junius lesen?}

Es war schon davon die Rede, dass auch für Rubens das Ehrbestreben erklärtermaßen ein wichtiger Beweggrund war. ${ }^{74}$ Doch war er wirklich mit dem aemulatio-Konzept des Franciscus Junius vertraut und hat er sich wirklich mit dessen Ideen auseinandergesetzt? Der bloße Besitz eines Buches sagt schließlich noch nichts darüber, ob der, dem es gehört, es auch gelesen hat. Und wenn man die neuere kunstwissenschaftliche Literatur zum Maßstab nimmt, mag man es kaum für besonders wahrscheinlich halten, dass die De pictura veterum libri tres tatsächlich einmal Leser fanden. ${ }^{75}$ Und mancher, der das Buch lobte, mag es gar nicht wirklich gekannt haben. Das lässt sich zum Beispiel von dem Maler Antoon Van Dyck mit gutem Grund vermuten, der das Buch wohl eher nicht gelesen hat. ${ }^{76}$ Den Hinweis darauf gibt ein Brief, den er am 14. August 1636 an Franciscus Junius sandte und der, zum Lob des Autors und des Werkes, im Vorspann der späteren Auflagen des Buches abgedruckt wurde (Abb. 1 und 2). ${ }^{77}$

73 „Altius tamen eriget animum, \& majores ad opus afferet spiritus artifex, qui præter utilissimum hunc æmulæ virtutis conatum, Apellem, Protogenem, Phidiam, Polycletum, in operis quasi societatem adsciscit; non tantum se consulens, quid in simili opere elaborando magnæ animæ, si fortè pingentibus fingentibusve nobis interveniant, suasuræ sint; verum etiam, quam de operibus nostris ad finem perductis opinionem sint habituræ. addit enim ad hanc curam etiam pudor stimulos, addit \& expectata laus, placendi cupidine secundos impetus mirifice augente." Junius 1637,151 (III, 1, \$15). Doch stärker als das zeitgenössische Publikum, das wird durch ein vorangestelltes Zitat aus der Schrift Vom Erhabenen des Pseudo-Longinus $(\$ 11)$ noch einmal nachdrücklich betont, wirke der Anhauch der Alten, jene heroischen Vorbilder, durch die auch nicht gerade enthusiastische Naturen zu begeisterten Genossen fremder Größe werden.

$74 \mathrm{Zu}$ Rubens' „zelo d'honore“ vgl. Anm. 42.

75 Vgl. Anm. 57. Man denkt unweigerlich an Gotthold Ephraim Lessings Sinngedichte an den Leser: „Wer wird nicht einen Klopstock loben? / Doch wird ihn jeder lesen?-Nein./Wir wollen weniger erhoben, /Und fleißiger gelesen sein." Barner (1989-2001), Bd. 2, 9.

76 Das soll nicht bedeuten, dass er mit dessen Thesen nicht vertraut war! Vgl. Büttner 2002a.

77 Vgl. Junius 1641; Junius 1694, fol. $+\dagger \dagger-\dagger+\dagger 3$ [sic]. Ellenius 1960, 94. Das Original des Briefes ist erhalten: The British Library, Harley MSS. 4935 (Epistole clarissimorum virorum), fol. 45. Faksimile in: Carpenter 1844, nach 53. Eine kritische Edition besorgte van Romburgh 2004, Nr. 110, 579 f. 
Peter Paul Rubens und Franciscus Junius

339

Myp thecre.

en Basom lanwwer heef my bys soé vedex poforiden het Excemplax Vanve' wertf De guttura vetrum. Develothy

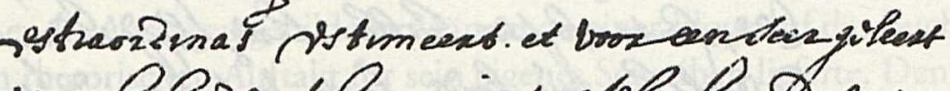

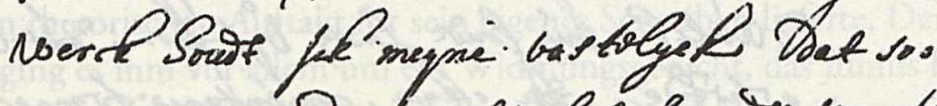
angineam aindecosite foe fos tot leverth

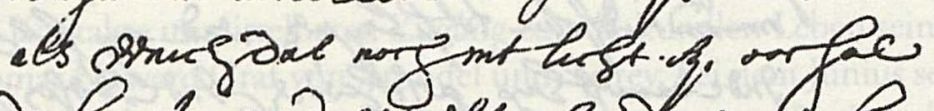

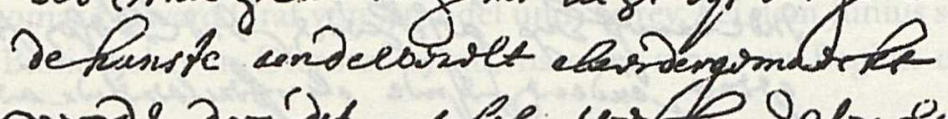

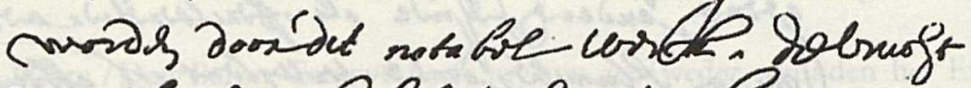

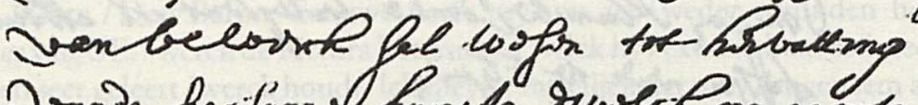
vande berteorgh hanst. Tuver langpoote - losie ende fonturst boonden-cuttairfe

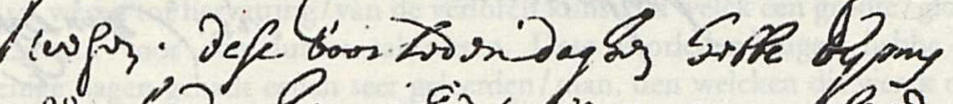

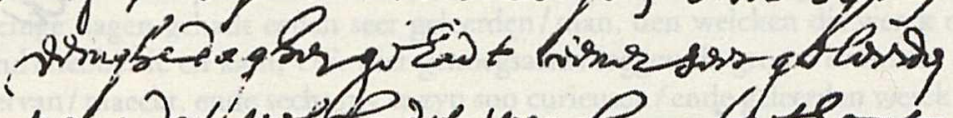

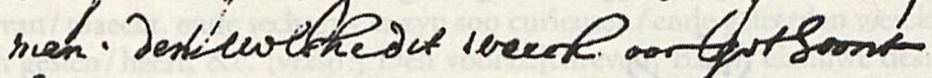
Sobbe. is en an ve met quice fuem degpos Sc proste stmathe dw hy Jaerban

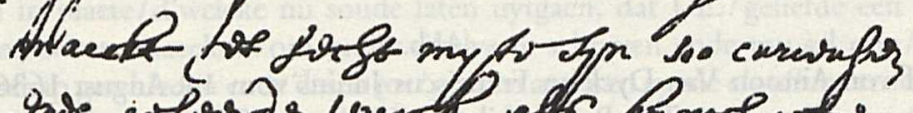

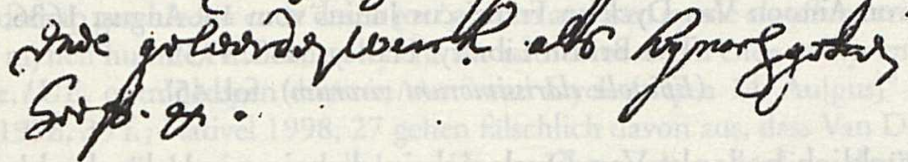

Abb. 1:

Brief von Antoon Van Dyck an Franciscus Junius vom 14. August 1636, London, The British Library, Harley MSS. 4935 (Epistole clarissimorum virorum), fol. $45^{\mathrm{r}}$. 
340

Nils Büttner

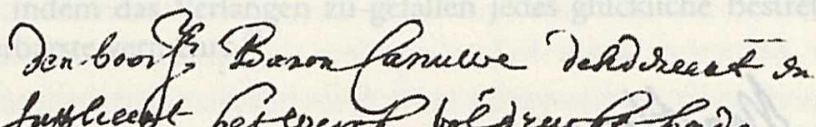
Suplecute has event bédruntar Dpoe. Coss osemplaen moforis Det alle. Cuneruge

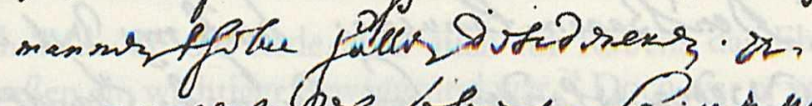

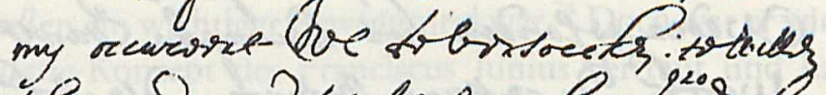

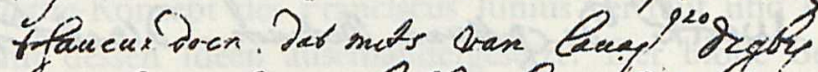

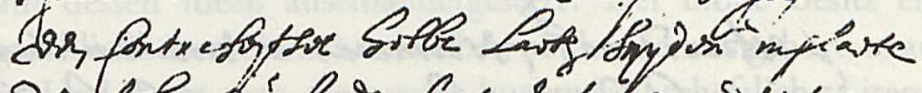

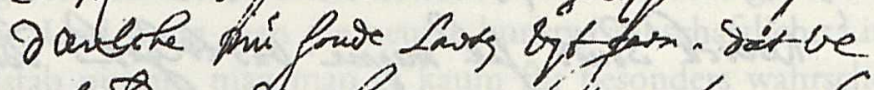

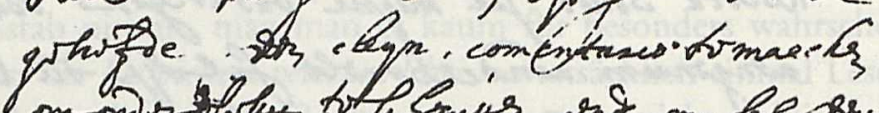

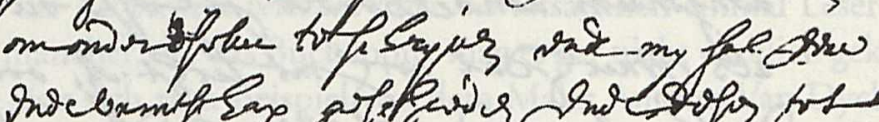

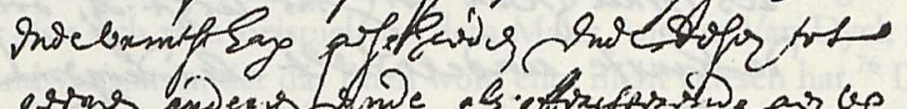

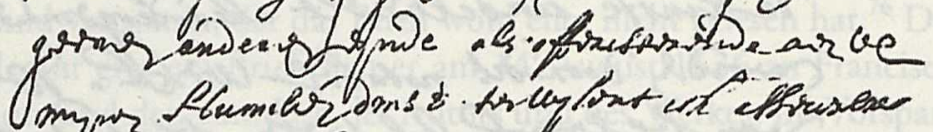

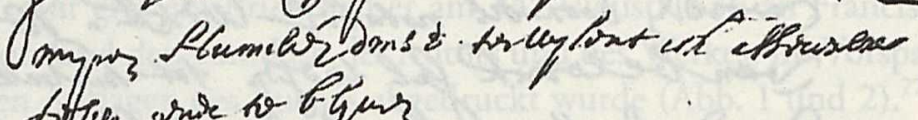

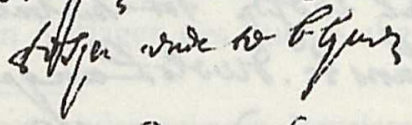

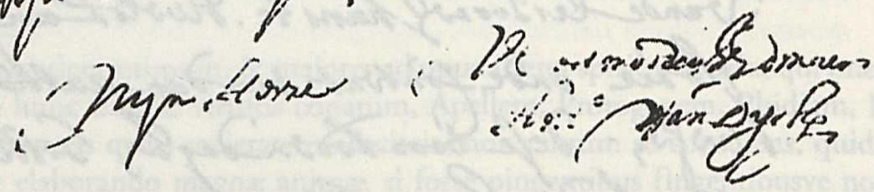

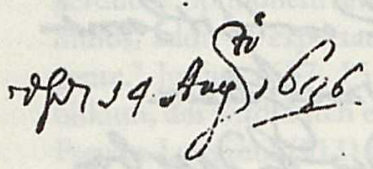

Abb. 2:

Brief von Antoon Van Dyck an Franciscus Junius vom 14. August 1636, London, The British Library, Harley MSS. 4935

(Epistole clarissimorum virorum), fol. $45^{\vee}$.

Ausdrücklich bedankt Van Dyck sich in dem in niederländischer Sprache abgefassten Schreiben für die Übersendung des Werkes De pictura veterum. Er habe es durch Edward Conway überbracht bekommen, „der es außerordentlich schätzt und für ein sehr gelehrtes Werk hält." Nach einigen Floskeln darüber, welche Ehre dem Autor aus seinem Werk erwachsen werde, fährt Van Dyck fort, dass er das Werk vor einigen Tagen einem 
gelehrten Mann gezeigt habe: „Ich kann Euer Ehren nicht genugsam sagen, welche hohe Wertschätzung er ihm entgegenbrachte. Und er sagte mir, es sei ein spannendes und gelehrtes Werk, wie er noch keines gesehen habe, etc. Und der vorgenannte Baron Conway wünscht und erhofft sich ein Exemplar, sobald das Werk gedruckt sei. ${ }^{\text {"78 }}$ Offensichtlich hatte Junius dem damals schon angesehenen Maler van Dyck sein Buch bereits vor dessen Drucklegung zugänglich gemacht, vielleicht um dessen Reaktion und Urteil noch berücksichtigen zu können. ${ }^{79}$ Mit keinem Wort äußert Van Dyck sich zu einer eigenen Leseerfahrung, vielmehr zitiert und kompiliert er die Aussagen gebildeter Männer zu einer Eloge auf das Buch, die nur den rhetorischen, Auftakt für sein eigenes Schreiben lieferte. Denn eigentlich ging es ihm vor allem um ein Widmungsgedicht, das Junius für einen seiner Kupferstiche verfassen sollte. Van Dyck hatte über seine vielfältigen Kontakte unmittelbaren Zugang zum kulturellen Leben seiner Zeit. ${ }^{80}$ Thomas Howard Graf von Arundel und Surrey, bei dem Junius seit 1621 als Bibliothekar in Diensten stand, hatte er schon zu Beginn der

78 „Myn Heere, /Den Baron Canuwe heeft my uyt zeé/weder gesonden het Exemplaer van UE. / werck de Pictura Veterum, d'welck hy / extraordinas estimeert, \& voor een seer geleert/werck houdt. Ick meyne vastelijck dat soo/aangenaem aen de weereld sal zyn dit werck/als eenig dat noch int licht zy. Ooc sal/ de kunste aen de weereld claerder gemaeckt/worden door dit notabel werck. De vrucht/van UE. werck sal wesen tot hervatting/van de verloren kunste, d'welck een groote/glorie ende content voor den auteur sal/wesen. Dese voorleden dagen hebbe by my/eenige dagen gehadt eenen seer geleerden/man, den welcken dit werck ooc getoond/hebbe. Ic en kann UE. niet genoegsaem/seggen de groote estimatie die hy daervan/maeckt, ende secht my te zyn soo curieusen/ ende geleerden werck als hy noch gesien/heeft, \&c. [verso:] Den voorsz. [chreven] Baron Canuwe desidereert en/supplieert het werck voldruckt zynde/een exemplaer neffens dat alle curieuse/mannen 't sullen desidereeren. En/my occurreert UE. te versoecken; te willen/ $t$ 'faveur doen, dat mits van Caval ${ }^{\text {ier }}$ Dighby/ een contrefeitsel hebbe laten snyden in plaete/d'welcke nu soude laten uytgaen, dat UE./geliefde een cleyn commentarie te maecken/om onder d'selve te schryven ende my sal eere/ende vriendschap geschieden ende desen tot/geenen anderen eynde als offereerende aen UE. / mynen humilen dienst, terwylent ick assureere / te zyn ende te blyven, / Myn Heere, /UE. ootmoedigen dienaer, /Ant ${ }^{\circ}$ van Dyck./ desen 14. Au[gus] ${ }^{\mathrm{ti}} 1636 .{ }^{\text {" }}$

79 Fehl 1998, 35 f.; Nativel 1998, 27 gehen fälschlich davon aus, dass Van Dyck ein gedrucktes Exemplar zugesandt bekam. Dem widersprechen allerdings der Text des Briefes und das Datum seiner Abfassung, denn das Werk war zu diesem Zeitpunkt noch im Druck. Vgl. van Romburgh 2004, 579, Anm. 105 a.

80 Zu Van Dycks Kontakten vgl. Hennen 1995, 11-15. Allgemein zu Van Dyck in England auch: Kat.-Ausst. Antwerpen/London 1999, 79-91 (Malcolm Rogers) mit weiterer Literatur; Jaffé 1996; Büttner 2002a, 24 f. Allgemein zum ArundelKreis auch Howarth 1985. 
zwanziger Jahre kennengelernt. Er verkehrte mit Kenelm Digby, Endymion Porter und anderen Angehörigen der englischen Aristokratie und wird fraglos auch Franciscus Junius persönlich begegnet sein. $\mathrm{Ob}$ er aber dessen Buch gelesen hat, lässt sich nicht mit Gewissheit sagen. Es ist nicht einmal sicher bezeugt, ob seine Lateinkenntnisse dafür ausgereicht hätten. ${ }^{81}$

\section{Rubens als Leser und Autor}

Ganz anders im Fall von Peter Paul Rubens, der fraglos gut genug Latein konnte, um das Buch zu würdigen. ${ }^{82}$ Auch ihm hatte der Autor das Werk zugänglich gemacht, wie ein Brief beweist, den Rubens am 1. August 1637 an Franciscus Junius sandte (Abb. 3 und 4). ${ }^{83}$ Das später vielfach abgedruckte Schreiben galt zu Beginn des 19. Jahrhunderts dem Kunsthistoriker Johann Dominik Fiorillo als sprechender Beweis der Latinität des Malers Rubens. ${ }^{84}$ Umso mehr muss es verwundern, dass bis heute niemand versucht hat, diesen zweisprachigen Brief einmal als sprachliches Kunstwerk zu würdigen.

Anrede und Eröffnung des Schreibens sind in niederländischer Sprache abgefasst, wobei Rubens sich vor allem für seine späte Reaktion auf die Übersendung des Buches entschuldigt. Sie sei nicht durch ihn verschuldet, sondern "door eenen van dese stadt ghenoemt Leon Hemelsroy", durch einen gewissen Leon van Hemelsroy, der als Wirt des Gasthauses „Het Gulden Hoofd“ die Sendung vermutlich im Auftrag eines Gastes an Ru-

81 Stewart 1990, 69, hat unter Verweis auf den genannten Brief vermutet, Van Dyck habe Latein gekonnt. Bis zum Auffinden weiterer Quellen, die das belegen könnten, bleibt diese Vermutung zweifelhaft. Der Idee von Nativel 1998, 27, dass Junius Van Dyck ein Exemplar der niederländischen Ausgabe zugänglich gemacht habe, ist unter Verweis auf den im Brief zitierten lateinischen Titel zu widersprechen. Vgl. dazu auch van Romburgh 2004, 579, Anm. 105a.

82 Zu Rubens' Lateinkenntnissen vgl. Büttner 2006, 28 und 166, Anm. 77.

83 Rooses/Ruelens 1887-1909, hier: Bd. 6, 179 f.; Van de Velde 2006, 160-164, $177 \mathrm{f}$. Die beste und präziseste Ausgabe bei van Romburgh 2004, 596-600, Nr. 114, die auch die verschiedenen Fehler und Irrtümer der älteren Editionen nachweist. Das Original des Briefes ist erhalten: The British Library, Harley MSS. 4935 (Epistole clarissimorum virorum), fol. 42-43.

84 Auch dieses Schreiben wurde verschiedenen Ausgaben von Junius' Buch als Widmung beigegeben. Vgl. Junius 1641; Junius 1694; van Romburgh 2004, 596, Anm. 1. Fiorillo 1815-1820, Bd. 3, $2 \mathrm{f}$. 


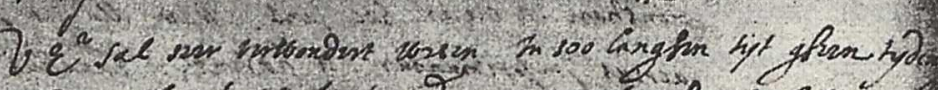

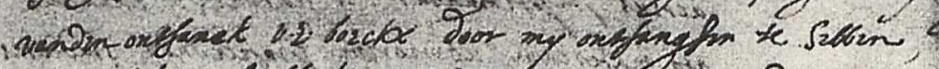

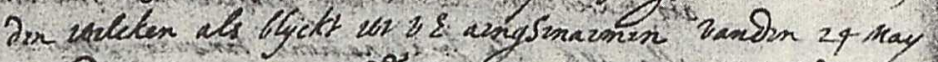

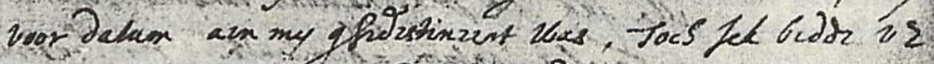

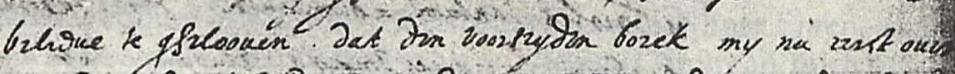

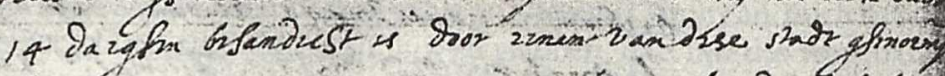

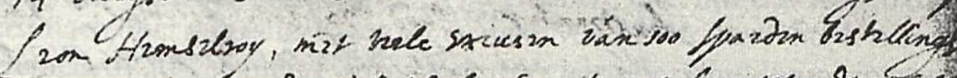

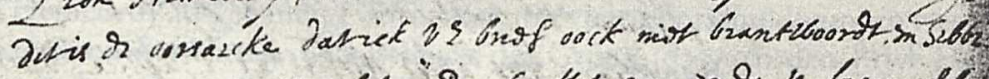

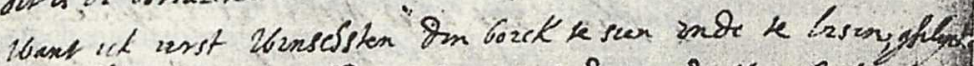

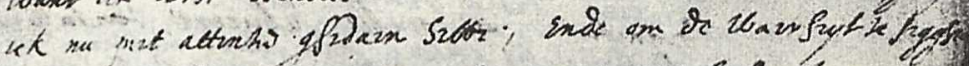

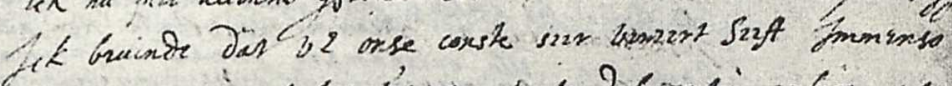

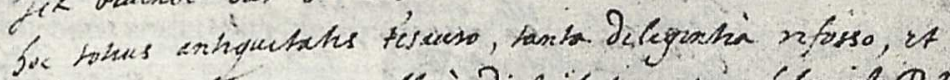

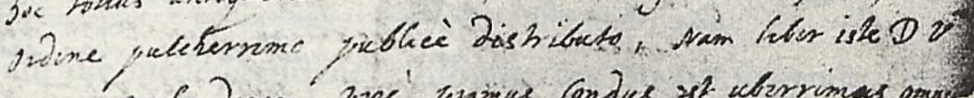

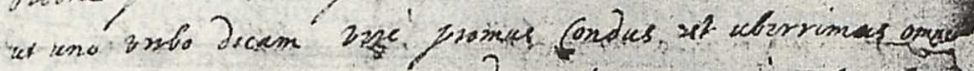

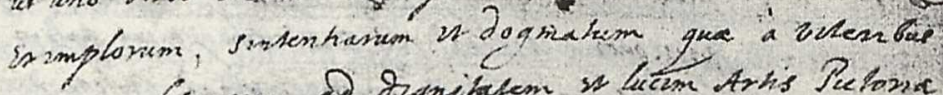

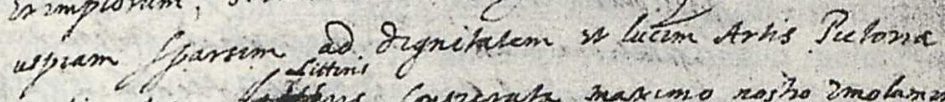

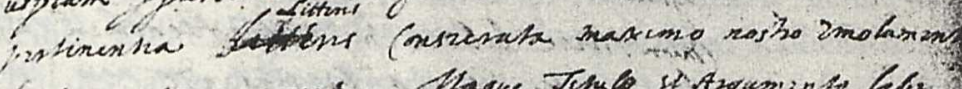

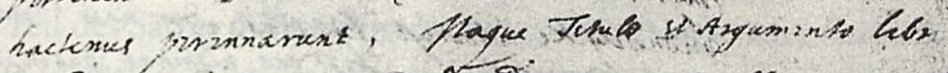

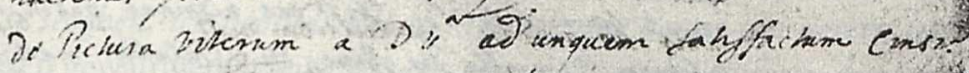

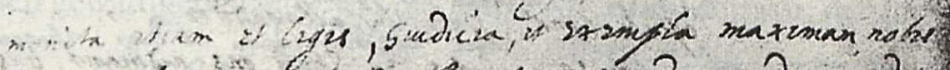

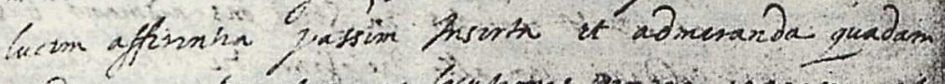

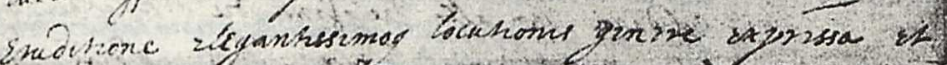

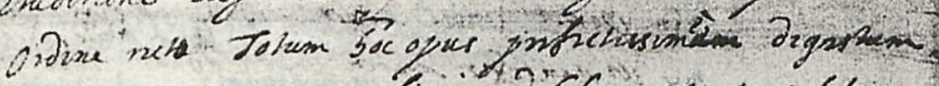

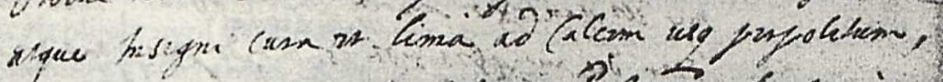

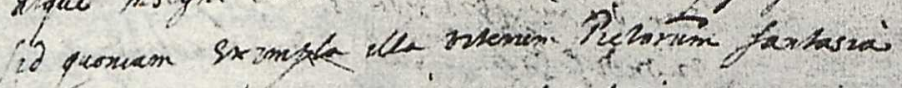

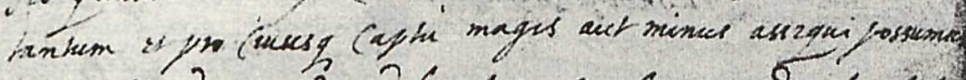

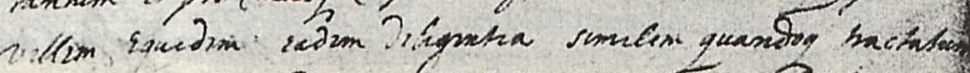

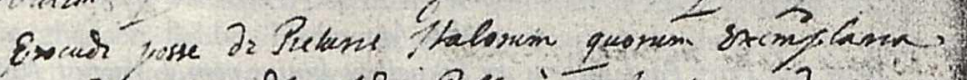

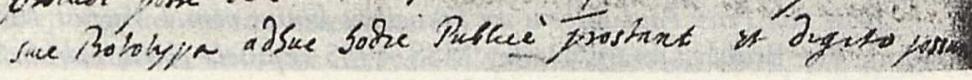

Abb. 3:

Brief von Peter Paul Rubens an Franciscus Junius vom 1. August 1637. London, The British Library, Harley MSS. 4935 (Epistole clarissimorum virorum), fol. $42^{\text {r }}$. 


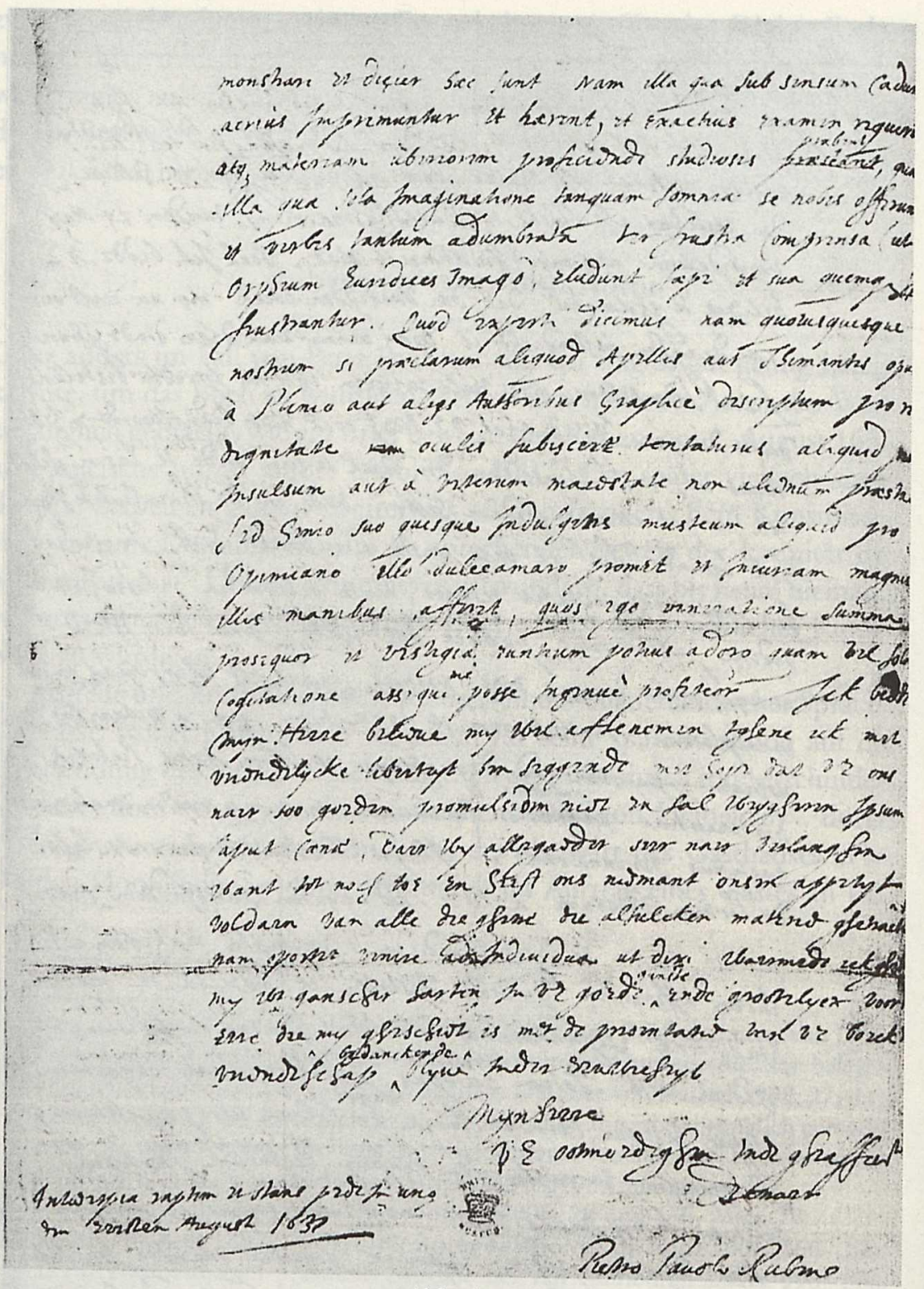

Abb. 4:

Brief von Peter Paul Rubens an Franciscus Junius vom 1. August 1637.

London, The British Library, Harley MSS. 4935 (Epistole clarissimorum virorum), fol. $42^{\mathrm{v}}$. 
bens ausgehändigt hatte. ${ }^{85}$ Für die Eröffnung seines Schreibens wählt Rubens die zeittypischen Höflichkeitsfloskeln, indem er unmittelbar unter der Anrede „Myn Heere“ den Satz mit der Wendung „U.E[del] ${ }^{\text {e“ }}$ beginnt, einer Formulierung, die in den folgenden zehn Zeilen noch sechsmal verwendet wird.

Sehr geehrter Herr, Euer Ehren werden wohl sehr verwundert gewesen sein, dass Euer Ehren nach so langer Zeit noch keine Mitteilung über den Empfang des Buches von Euer Ehren von mir erhalten haben, das Euer Ehren, wie aus Ihrem Briefe vom 24. Mai hervor geht, an diesem Datum an mich gesandt wurde. Doch bitte ich Euer Ehren, mir zu glauben, dass mir das vorgenannte Buch erst nach über vierzehn Tagen von einem Manne aus dieser Stadt namens Leon Hemelsroy ausgehändigt worden ist, mit vielen Entschuldigungen wegen der so späten Bestellung. Das ist auch der Grund, dass ich den Brief Euer Ehren noch nicht beantwortet habe, denn ich wollte das Buch vorher sehen und lesen, was ich nun mit Aufmerksamkeit getan habe. Und um die Wahrheit zu sagen, ich finde, dass Sie unsere Kunst hoch geehrt haben. ${ }^{86}$

Mitten im Satz endet hier der in niederländischer Sprache abgefasste Teil des Briefes.

Der auf die niederländische Eröffnung des Briefes folgende Text ist vermutlich deshalb in Latein abgefasst, weil Rubens das als die einzig angemessene Reaktion auf ein gelehrtes Werk erschien und weil er dem Gesagten durch die Verwendung literarischer Anspielungen mehr Nachdruck verleihen wollte. ${ }^{87}$ Inhaltlich und grammatikalisch schließt der lateinische Teil des Satzes unmittelbar an das vorher gesagte an. „Ende om de waerheyt te segghen, ick bevinde dat U.E.[dele] onse konste seer vereert heeft, durch diesen gewaltigen Schatz, der das ganze Altertum umfasst, der mit so

85 Antwerpen, Stadsarchief, PK 704 (Requestboek 1613-1614), fol. 165․ Vgl. auch Van de Velde 2006, 181, Anm. 38.

86 „Myn Heere,/U.E[del] $]^{\mathrm{c}}$. sal seer verwondert wesen in soo langhen tijt gheen tijdinghe/vanden ontfanck U.E. [dele] boeckx door my ontfanghen te hebben, / den welcken als blijckt uyt U.E. [dele] aenghenamen van den 24 May/voor datum aen my ghedestineert was. Toch ick bidde U.E. [dele]/believe te gelooven, dat den voorseyden boeck my nu eerst over/ 14 daeghen behandicht is door eenen van dese stadt ghenoemt/Leon Hemelsroy, met vele excusen van so spaeden bestellinghe. / Dit is de oorsaecke dat ick U.E. [dele] brief oock niet beantwoordt en hebbe/want ick eerst wenschten den boeck te sien ende te lesen, ghelyck/ick nu met attentie ghedaen hebbe. Ende om de waerheyt te segghen/ick bevinde dat U.E.[dele] onse konste seer vereert heeft."

87 Van de Velde 2006, 160, hat der von Aldrich/Fehl/Fehl 1991, Bd. 1, LXVI, ausgesprochenen Vermutung, dass Rubens den Brief schon mit Blick auf eine spätere Veröffentlichung zweisprachig abgefasst habe, mit guten Gründen widersprochen. So auch van Romburgh 2004, 597 f., Anm. 4. 
großem Fleiß gesammelt und in schönster Ordnung an die Öffentlichkeit gebracht ist. ${ }^{\text {"88 }}$ Die lateinische Wendung "totius antiquitatis thesauro" impliziert dabei mehr als einen "Schatz, der das ganze Altertum umfasst“.

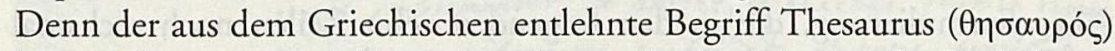
hatte sich zu Rubens' Zeit schon längst als Bezeichnung für lexikalische Wörtersammlungen und Nachschlagewerke etabliert. ${ }^{89}$ Mit den zunehmenden philologischen Bemühungen, möglichst exakte Textausgaben zu erstellen, war im Verlauf des 16. Jahrhunderts unter dem Begriff „Thesaurus" zugleich eine stetig wachsende Zahl von Wörterbüchern, Wortlisten und Florilegien publiziert worden, in denen die für das gebildete Sprechen und Schreiben unerlässlichen loci communes der klassischen Literatur übersichtlich dargeboten wurden. Rubens zum Beispiel besaß die Electa Plautina des Johann Philipp Wängler, die auf dem Titelblatt als "Thesauro quodam Antiquitatis“ angepriesen wurden, „gewissermaßen ein Schatz des Altertums“. ${ }^{90}$ Die Tatsache, dass Rubens nicht nur eine 1619 bei Willem Jansz. Blaeu in Amsterdam edierte Ausgabe der Werke des Plautus besaß, die er am 25. Februar 1633 für einen Gulden 16 Stuiver bei PlantinMoretus erworben hatte, sondern auch Wänglers Electa Plautina ist für das Verständnis seines Briefes an Junius sicher nicht ohne Belang. ${ }^{91}$ Denn Rubens' Lob für Junius' Werk bemüht ein Sprachbild aus den Komödien des Plautus. „Denn dieses Buch von Euer Herrlichkeit ist“, so Rubens, „um es mit einem Wort zu sagen, wahrhaft ein ergiebiger Haushofmeister, voll von Beispielen, Aussprüchen und Lehren, die sich, von den Alten irgendwo

88 „Immenso/hoc totius antiquitatis thesauro, tanta diligentiâ refosso, et/ordine pulcherrimo publicè distributo."

89 Der Begriff Thesaurus wurde erstmalig um 1265 von dem Florentiner Brunetto Latini (zw. 1210 und 1220-1294/95) als Bezeichnung einer systematisierten Enzyklopädie verwendet. Vgl. Vatteroni 2004, 147-156. Ihm folgten zahlreiche weitere "Thesauri“, zumeist umfangreiche Werke, die möglichst vollständig ganze Wissensgebiete umfassten. Am berühmtesten sind bis heute die diesen Titel führenden lexikographischen Werke von Vater und Sohn Estienne (lat. Henricus und Robertus Stephanus), der Thesaurus linguae Latinae und der Thesaurus linguae graecae. Diese 'Schatzkammern' der lateinischen und griechischen Sprache dürften Rubens bekannt gewesen sein. In der Bibliothek von Albert Rubens ist beispielsweise der von Robertus' Bruder Carolus Stephanus edierte Thesavrvs M. Tvllii Ciceronis (Paris: Stephanus 1556) nachgewiesen. Vgl. Arents 2001, 366, fol. 28, kol. 2.

90 Wängler 1617. In einem Exemplar im Nachlass von Albert Rubens nachgewiesen. Vgl. Arents 2001, 356, fol. 18, kol. 2.

91 Rubens besaß die Ausgabe M. Accii Plauti comoediae superst. [ites] XX. Amsterdam: Blaev, 1619. Vgl. Arents 2001, 193, E167. 
verstreut, auf das Lob und die Betrachtung der Malkunst beziehen, die durch Buchstaben verewigt und bis auf den heutigen Tag $\mathrm{zu}$ unserem größten Nutzen überliefert worden sind. " ${ }^{\text {"2 }}$ Die von Rubens verwandte Wendung, "promus condus [...] uberrimus" wurde in der vielzitierten Übersetzung von Otto Zoff 1918 ,eine reich beladene Tafel“ ${ }^{93}$ Friedrich Goeler von Ravensburg hatte die Stelle 1882 in Anlehnung an die englische Übersetzung von Noël W. Sainsbury aus dem Jahr 1859 als eine „überreiche Schatzkammer" übersetzt, „a rich storehouse", wie auch Ruth Saunders Magurn übersetzte, woraus in der niederländischen Übersetzung von Carl van de Velde "een overvloedige voorraadkamer" wurde. ${ }^{94}$ Es ist das Verdienst von Ulrich Heinen, eine der lateinischen Wortbedeutung nähere Übersetzung vorgeschlagen zu haben, indem er "promus condus" mit „Küchenmeister" übersetzte. ${ }^{95}$ Er verwies zugleich darauf, dass Rubens den Begriff auch in einem Trostbrief verwandte, den er am 15. September 1629 an Jan Caspar Gevaerts sandte und in dem er diesen ebenfalls als „promus condus “ bezeichnete: „Ad Antonium tuum te ablego, cujus e divitate penu, tanquam promus condus, amicis etiam quod distribuas habes. "96 "Ich sende Dich weg zu Deinem Antonius [gemeint ist Kaiser Marc Aurel], von dessen reicher Speise Du wie ein Küchenmeister noch etwas den Freunden auszuteilen hast ", übersetzte Ulrich Heinen die betreffende Stelle. ${ }^{97}$ Die in beiden Briefen als Lob intendierte Bezeichnung "promus condus" ist in der antiken Literatur verschiedentlich belegt, am prominentesten sicher in den Komödien des Plautus. ${ }^{98}$ Das erweist schnell ein Blick in Wänglers Electa

92 „Nam liber iste D. [ominationis] V[estr] $]^{x} /$ ut uno verbo dicam verè promus condus est uberrimus omni[um]/ exemplorum, sententiarum et dogmatum quæ à veteribus/uspiam sparsim ad dignitatem et lucem Artis Pictoriæ/pertinentia litteris consecrata maximo nostro emolumento/ hactenus perennarunt. "

93 Zoff 1918, 460.

94 Sainsbury 1859, 159; Goeler von Ravensburg 1882, 199; Magurn 1971, 407; Van de Velde 2006, 179.

95 Ulrich Heinen, in: Kat.-Ausst. Braunschweig 2004, 27, übersetzt die Passage mit „Küchenmeister, der überaus reich ist an Vorbildern, Sinnsprüchen und Lehrsätzen“. In der englischen Übersetzung von van Romburgh 2004, 597: „For Your Lordschip's book - to say so in a single word - is truly a distributing steward rich with all examples".

96 Rooses/Ruelens 1887-1909, Bd. 5, 197. Bei van Romburgh 2004, 598, Anm. 5, der Hinweis auf einen Brief, den Franciscus Junius am 1. Januar 1618 an Johan Bosman sandte (ebd., 159, Nr. 22), in dem die Wendung ebenfalls begegnet.

97 Ulrich Heinen, in: Kat.-Ausst. Braunschweig 2004, 255.

98 So bei Hor. sat. II, 2, 16; Cic. Oecon. fr. 10 und Auson. eist. XXII, 20. Am prominentesten fraglos bei Plaut. Pseud. 608. 
Plautina, wo unter dem Lemma „Servorum, servitutis [...]“ auch von den "Servis variæ dabantur provinciæ in familiari" die Rede ist und die Funktion der atrienses und promi condi erläutert wird. ${ }^{99}$ Folgt man den dort gegebenen Verweisen, stößt man schnell auf eine Passage aus der Komödie Pseudolus, wo deren Titelperson sich ihrem Gesprächspartner Harpax als "Condus promus" vorstellt: ${ }^{100}$

Harpax: Was soll das Wort bedeuten?

Pseudolus: Ich bin der Haushofmeister, der Einnahmen und Ausgaben zu besorgen hat.

Harp.: Quasi der Hausmeister?

Ps.: Nein, der steht unter mir.

Harp.: Dienst Du als Sklave, oder bist Du frei?

Ps. : Nein für jetzt bin ich noch Sklave. ${ }^{101}$

Die letzte Formulierung ist dabei von besonderer Bedeutung, wenn man verstehen will, was Rubens mit seiner literarischen Anspielung auf die plautinische Komödie bezweckt. Durch seine reichen, nie ermüdenden Dialoge gehört der Pseudolus zu den reichsten und reifsten Stücken des Plautus. Dabei ist es gerade die Hauptfigur, der Sklave Pseudolus, der durch die Schlagfertigkeit seines Witzes das Stück und die Handlung bestimmt. In einem Spiel mit der Handlungstypik römischer Komödien lässt Plautus seine Hauptfigur zunehmend in die Rolle ihres eigenen Dichters hineinwachsen, die einnehmen zu wollen die Figur schon zum Auftakt des Stückes behauptet: „Doch wie ein Dichter, der, sobald er zur Schreibtafel greift, sucht und schließlich doch entdeckt, was nirgends ist, der der Wahrheit ähnlich macht, was Lüge ist, so will ich jetzt ein Dichter sein. "102 Es ist niemand anders als Plautus selbst, der durch die Figur des Pseudolus spricht, wobei diese Identifikation des Dichters mit seiner Titelfigur auch durch eine von Cicero überlieferte Anekdote wahrscheinlich gemacht wird, in der es heißt, dass dieses Stück dem Herzen des Dichters besonders nahe gestanden habe. ${ }^{103}$ Die Wendung "promus condus" ist mithin als Allusion des Dichters Plautus zu lesen, um dessen Ruhm und

99 Wängler $1617,531-547$, bes. 534 .

100 Plaut. pseud. II, 2 (608-610).

101 „Harpax: Quid istuc verbist? Pseudolus: Condus promus sum, procurator peni./ Harp. Quasi te dicas atriensem. Ps. Immo atriensi ego impero./ Harp. Quid tu, servon es an liber? Ps. Nunc quidem etiam servio."

102 Plaut. pseud. I, 4 (401-404): ,sed quasi poeta, tabulas cum cepit sibi, / quaerit quod nusquamst gentium, reperit tamen, / facit illud veri simile, quod mendacium est, / nunc ego poeta fiam."

103 Cic. Cato maior XIV, 50. 
Anerkennung sich Justus Lipsius, der Lehrer von Philipp Rubens, dem Bruder des Malers, nachdrücklich bemüht hatte. ${ }^{104}$ Lipsius hatte Plautus als „decima musa“, als „zehnte Muse“, gepriesen. ${ }^{105}$ Doch selbst wer die Schrift des Lipsius nicht gelesen hatte, mochte mit den zahllosen antiken Anspielungen auf die Eleganz der Sprache des Plautus vertraut sein, die von Autoritäten wie Cicero und Quintillian vertreten wurde. ${ }^{106}$ „Musas plautino sermone locuturas fuisse, si latine loqui vellent", hatte Letzterer geschrieben: „Wenn die Musen Latein hätten sprechen wollen, dann hätten sie die Sprache von Plautus gesprochen". ${ }^{107}$ Und genau dieses Lob wird über die Anspielung auf den „promus condus" nun auch dem von Rubens gelobten Autor zuteil. Die philologisch gebildeten Adressaten der Briefe, in denen Rubens sich dieser Anspielung bediente, dürften das der Formulierung verbundene Lob unmittelbar verstanden haben. ${ }^{108}$

\section{7. „ad unguem satisfactum censeo“}

„Deshalb sage ich“, fährt Rubens fort, „dass Euer Gnaden dem Titel Von der Malerei der Alten aufs Genaueste Genüge getan haben. "109 Die von Rubens hier verwandte Anspielung auf die „Nagelprobe“, „ad unguem satisfactum censeo", geht ursprünglich auf Plutarch zurück und wird von Franciscus Junius im Catalogus artificum im Lebensbericht des Bildhauers Polyklet zitiert. ${ }^{110}$ Nach diesem Lob fährt Rubens mit dem in einem überbordend langen Satz formulierten Kompliment fort, „dass Sie mit der Anführung

104 Van der Poel 1999.

105 Lipsius 1675, Bd. 2, 155 f. (ep. cent. II, 31), Brief an Josias Mercerus vom 10. Oktober 1587.

106 Cic. De Officiis, I, 104; Quint. ist. X, 1, 99; Gellius, n. att. I, 7, VII, 17; Macr. sat. 2, $1,10$.

107 Quint. ist. X, 1, 99.

108 Als topische Wendung hielt der Promus-condus auch in die Literatur Einzug. Vgl. Reinerus (Regnerus) Neuhusius: Florilegium Philologicum sive Veterum et Recentiorum Eloquentiae Promus-Condus in usum Illustrium Scholarum West-Frisiae. Amsterdam 1650; Neudruck: Amsterdam 1658.

109 „Itaque titulo et argumento libri de Picturâ Veterum à D. V̀a . ad unguem satisfactum censeo."

110 Plut. moralia 86 A, 636c. Junius 1694, 168: „Plutarchus Symposiacon libro II, probl. 3 [...] Artes initio rudia atque informia fingunt opera, deinde tandem singula suis formis articulatim perficiunt. Unde \& Polycletus fictor dixit, Opus tunc esse difficilium, cum ad unguem exigitur lutum."; Aldrich / Fehl/ Fehl 1991, Bd. 1, 327 (983B). 
von den überall eingeflochtenen Aussprüchen, Lehren, Urteilen und Beispielen, zu unserer größten Belehrung so geeignet, Ihr Ziel erreicht haben und dass alles mit bewundernswürdiger Wissenschaft und in gewähltem Stile dargestellt, in richtiger Reihenfolge gründlich behandelt und mit außerordentlicher Sorgfalt und durch die künstlerische Feile bis zum Ende durchgeführt ist. " ${ }^{111}$ Wenn Rubens hier die von Junius so wohlgeordneten „exempla“, „sententiae“ und "dogmata“ lobt, folgt er damit in etwa „der um 1600 gängigen Einteilung des Rhetorikunterrichts in praecepta, exempla, imitatio“. ${ }^{112}$ Besonderes Lob erfährt dabei die sorgsame Durcharbeitung des Traktates, die mit „insigni curâ et limâ" erfolgt sei, „mit außerordentlicher Sorgfalt" und der durch Horaz und andere Autoren zitierten "künstlerische Feile“, die auch Junius selbst in seinem Traktat anführt, in dem die Zeit als "einzigartige Feile und Gesetz der Kunst" bezeichnet wird, „unica lima \& lex artium“. ${ }^{113}$ Dem ausführlichen Lob folgt eine inhaltliche Stellungnahme, die zu zahlreichen Missverständnissen Anlass gegeben hat.

Aber da wir nun einmal jene Beispiele der alten Maler nur mit der Phantasie und je nach besonderer Befähigung und Anlage des Einzelnen bald mehr, bald weniger erfassen können, so möchte ich gerne, dass mit gleicher Sorgfalt einmal eine ähnliche Abhandlung verfasst werden könnte über die Malerei der Italiener, deren Beispiele oder Prototypen bis heute der öffentlichen Anschauung zugänglich sind und auf die man mit den Fingern zeigen und sagen kann: das sind sie. ${ }^{114}$

Die den Satz abschließende Formulierung „monstrari et dicier hæc sunt", die zugleich den Text auf der Rückseite des Briefbogens eröffnet, ist nicht nur wieder als literarische Allusion lesbar, sondern zugleich bezeichnend für

111 „Monita etiam et leges, giudicia, et exempla maximam nobis/lucem afferentia passim inserta et admiranda quadam/eruditione elegantissimoq[ue] locutionis genere expressa et/ordine recto totum hoc opus perfectissimè digestum/atque insigni curâ et limâ ad calcem usque perpolitum."

112 Heinen 1996, 194, Anm. 95.

113 Junius 1637,15 (I, 3, \$1): „Artes certè primitùs nascentes atque etiamnum imperfectas, per manus aliquamdiu tradidere priores, neque aliud quàm nudam rudium observationum sylvam in unum congesserunt; donec tempus, unica lima \& lex artium, temerè congesta distinxit, inque artis justæ formam contraxit.“

114 „Sed quoniam exempla ille veterum Pictorum fantasiâ/ tantum et pro cujusq[ue] captu magis aut minus assequi possumus/vellem equidem eadem diligentia similem quandoq[ue] tractatum/excudi posse de Picturis Italorum quorum exemplaria/sive prototypa adhuc hodie publicè prostant et digito possunt/ [verso:] monstrari et dicier hæc sunt." 
Rubens' lateinisches Stilideal. ${ }^{115}$ Statt einfach „dici“ zu schreiben, verwendet Rubens den archaisch anmutenden Infinitiv Präsens Passiv „dicier“, der von einem für Fragen des lateinischen Stils sensiblen Zeitgenossen als Hinweis auf Rubens' Zugehörigkeit zum Lipsius-Kreis gelesen werden konnte. Zugleich machte diese Wendung die literarische Anspielung auf die erste Satire des Persius sichtbar, in der sich im Kontext einer Reflektion über den literarischen Stil der Hinweis auf jenes Glück findet, „wenn man mit dem Finger zeigt, und sagt: der ist's!“, „At pulchrum est digito monstrari, et dicier, hic est" ${ }^{116}$

Unter Verweis auf diese Textstelle ist der Brief von der kunsthistorischen Forschung oft fälschlich als Hinweis auf einen Dissens zwischen dem Maler und dem Theoretiker gelesen worden und als Zeichen dafür, dass Rubens die von Junius propagierte Orientierung am klassischen Vorbild abgelehnt habe. ${ }^{117}$ Dagegen spricht jedoch, wie Ulrich Heinen schon 1996 zu Recht betont hat, sowohl die von Rubens praktizierte Adaption von Junius' literarischen Stilprinzipien, als auch die Tatsache, dass der Brief in den späteren Ausgaben des Buches einleitend abgedruckt wurde. ${ }^{118}$ Was Rubens äußert, ist tatsächlich keine Fundamentalkritik an den von Junius dargelegten Grundlagen der antiken Kunsttheorie. Er fordert vielmehr die von Junius auch den Malern abverlangte Qualität der evidentia ein, eine die Überzeugungskraft des Gesagten stärkende Exemplifikation am Beispiel von "Picturis Italorum", womit gleichermaßen italische wie italienische Beispiele gemeint sein könnten. ${ }^{119}$ Allerdings legt der Begriff nahe, dass Rubens hier weniger die auf italienischem Boden bewahrten Zeugnisse antiker Kunst als vielmehr die Werke der neueren italienischen Malerei meint, um die von Junius postulierten Qualitätskriterien anschaulich zu illustrieren. ${ }^{120} \mathrm{Um}$ seiner Forderung rhetorisch Nachdruck zu verleihen, beschwört Rubens die notwendige, auch von Cicero, Horaz und Quintilian

$115 \mathrm{Zu}$ Rubens' lateinischem Stilideal vgl. die Ausführungen von Andreas Thielemann [im Druck]. Ich danke dem Verfasser für die Überlassung seines beeindruckenden Manuskriptes!

116 Pers. sat. I, 28.

117 Vgl. u. a. Emmens 1979-1981, Bd. 2, 202; Ellenius 1960, 92, 94-96, weitere Nachweise bei Heinen 1996, 201, Anm. 120.

118 Heinen 1996, 201, Anm. 120, hat erstmals auf dieses Missverständnis hingewiesen.

119 Van de Velde 2006, 182, Anm. 48, hat das zu Recht angemerkt.

120 Heinen 1996, 202, Anm. 123: „In seiner Argumentation folgt Rubens einem Gedankengang Van Manders, der ebenfalls hervorhebt, dass die antiken Autoren zwar die Vorstellung, nicht aber die Anschauung anregen können. Dies vermöge dagegen die italienische Kunst." 
vom Redner und Dichter geforderte Sinnlichkeit: ${ }^{121}$ „Denn das, was in die Sinne fällt", so Rubens weiter, „prägt sich schärfer ein, haftet besser und erfordert eine genauere Prüfung, gewährt auch dem Studierenden eine reichere Möglichkeit Fortschritte zu machen als jenes, was nur in der Vorstellung, gleich wie ein Traum, sich uns darbietet. "122 Es ist die letztlich auf Aristoteles zurückgehende Vorstellung von der größeren Anschaulichkeit des sinnlich Erfahrbaren, auf die Rubens hier verweist und die auch Junius in seinem Traktat zitiert. ${ }^{123}$ "Nam illa quæ sub sensum cadunt acrius imprimuntur et hærent“, schreibt Rubens, denn „was nur mit Worten skizziert werden kann, wird selbst bei dreifachem Bemühen (wie dem Orpheus das Bild der Eurydike), dennoch oft wieder entschwinden und jeder wird in seiner Hoffnung enttäuscht. “124 Die Wendung „ter frustra comprensa" alludiert einen vielzitierten Vers aus der Aeneis Vergils und verleiht dem im Text beschworenen Bild „ut Orpheum Eurydices imago" mehr Nachdruck. ${ }^{125}$ Der Hinweis auf die bei Ovid berichtete tragische Geschichte von Orpheus und Eurydike ließ sich dabei zugleich auf Rubens' eigene künstlerische Praxis beziehen. Nicht lange bevor er an Junius schrieb, hatte Rubens die Flucht von Orpheus und Eurydike aus dem Reich des Hades nämlich selbst ins Bild gesetzt (Abb. 5). ${ }^{126}$

Das Bild war im Rahmen eines Großauftrages entstanden. Am 20. November 1636 meldete Kardinal-Infant Ferdinand an seinen Bruder, den spanischen König Philipp IV., dass Rubens die Entwürfe für den königlichen Jagdsitz Torre de la Parada bereits begonnen habe. Einige Wochen später, am 6. Dezember, konnte er berichten, dass die gesamte Werkstatt fieberhaft an der Ausführung der mehr als hundertzwanzig bestellten Gemälde arbeite. „Rubens ist sehr von dieser Aufgabe beansprucht“, schrieb Ferdinand. „Man sagte mir, dass er die Arbeit bereits unter den besten seiner Maler aufgeteilt habe, dass er die Zeichnungen aber

121 Belege hierfür bei Quint. inst. VIII, 3, 61 und IX, 2, 40. Für weitere Belege vgl. Hübner 2010, 119-148.

122 „Nam illa quæ sub sensum cadunt/acrius imprimuntur et hærent, et exactius examen requirunt/atque materiam uberiorem proficiendi studiosis præbent, quàm/illa quæ sola imaginatione tanquam somnia se nobis offerunt."

123 Vgl. Simoni 1566; Junius 1637, bes. $37 \mathrm{f}$.

124 „Et verbis tantum adumbrata ter frustra comprensa (ut/Orpheum Eurydices imago), eludunt sæpè et suâ quemq[ue] spe/frustrantur."

125 Verg. aen. II, 793: „ter frustra comprensa manus effugit imago.“

126 Peter Paul Rubens: Orpheus und Eurydike. Öl auf Leinwand, $180 \mathrm{~cm} \times 270 \mathrm{~cm}$. Madrid, Prado. Vgl. Ov. met. X, 57-81. Der Hinweis auf dieses Bild schon bei Aldrich/Fehl/Fehl 1991, Bd. 1, 328. 


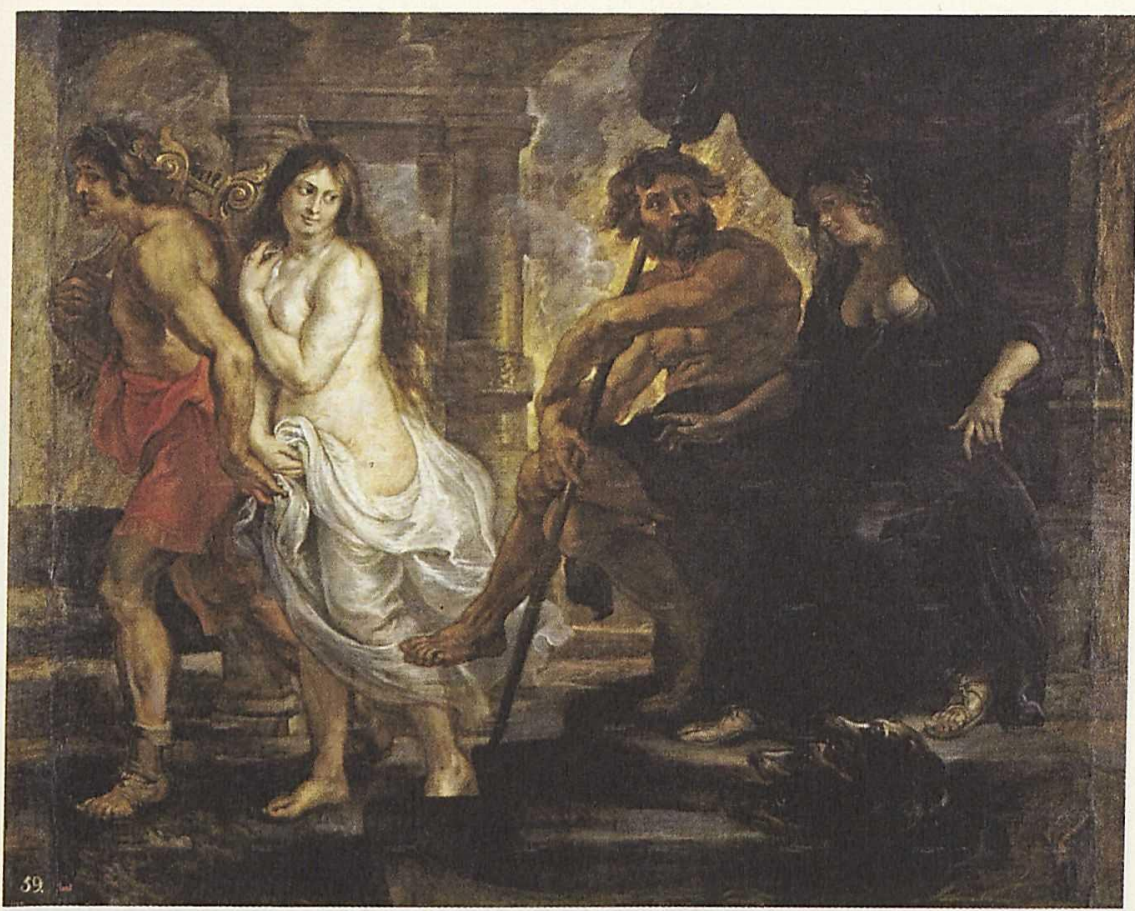

Abb. 5:

Peter Paul Rubens, (1637/1638): Orpheus und Eurydike.

Öl auf Leinwand, $180 \times 270 \mathrm{~cm}$. Madrid, Prado.

alle selbst anfertigen möchte, mit Ausnahme jener, die er Snyders anver-

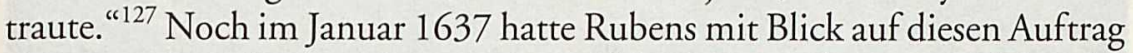
eine neue Ausgabe der Metamorphoseon libri XVerworben, um sich bei der Ausführung der Bilder unmittelbar am klassischen Text zu orientieren. ${ }^{128}$ Diese Tatsache vermag zugleich die nächstfolgende Passage in Rubens' Brief an Junius erklären.

Das können wir aus Erfahrung sagen, denn wer von uns ist imstande, irgendein berühmtes Werk des Apelles oder des Thimantes, das von Plinius oder anderen Autoren malerisch beschrieben ist, wenn er versucht, es sich in seiner ganzen Würde vor Augen zu stellen, wer von uns wird etwas nicht abge-

127 Rooses/Ruelens 1887-1909, Bd. 6, 170 f., Nr. 823, Brief vom 20. November 1636. Ebd., 171 f., Nr. 824, Brief vom 6. Dezember 1636: „En las pinturas se va trabajando, y Rubens está muy encargado de la obra. Diceme las tiene ya muy repartidas á los mejores pintores, pero que él las quiere dibujar todas menos las de Esneire [d.i. Snyders N.B.]."

128 Vgl. Arents 2001, 198, Nr. E191. Vgl. McGrath 1997, Bd. 1, 64 f.; Bd. 2, 49-51. 
schmacktes und von der Würde der Alten nicht abweichendes präsentieren; sondern jeder wird, seinem eigenen Empfinden folgend, anstelle jenes bittersüßen Weins aus dem Jahr des Opimius irgendeinen Most kredenzen und so die Manen jener großen Künstler beleidigen, deren Spuren ich eher folge und die ich zu tief verehre, als dass ich sagte, ihnen gleichkommen zu können und sei es auch nur in Gedanken. ${ }^{129}$

Damit endet die geschlossene lateinische Passage des Briefes, wobei auch im Schlussteil lateinische Einsprengsel begegnen, in denen die Speisemetaphern eine Fortsetzung finden, deren erste im Verweis auf den „Opimianus" begegnet, den von zahlreichen klassischen Schriftstellern gerühmten besten Wein aller Zeiten. ${ }^{130}$

\section{8. "Quod experti dicimus"}

„Das können wir aus Erfahrung sagen“, leitete Rubens diesen Abschnitt seines Briefes ein. Und tatsächlich sprach er als Experte, da er selbst immer wieder die literarisch überlieferten antiken Bildbeschreibungen und poetischen Ekphrases zum Ausgangspunkt eigenen Arbeitens genommen hatte. So hatte er beispielsweise die von Philostrat so eindringlich beschriebenen Landschaftsbilder aufgegriffen und sie in eigene Bilder überführt. ${ }^{131}$ Oder, um ein anderes Beispiel anzuführen, zwischen 1612 und 1615 hatte er zusammen mit Osias Beert mit einem von Plinius beschriebenen Meisterwerk der Antike gewetteifert. Das Bild zeigt den Maler Pausias und die Blumenflechterin Glycera (Abb. 6). ${ }^{132}$

129 „Quod experti dicimus nam quotusquisque / nostrûm si præclarum aliquod Apellis aut Timanthis opus / à Plinio aut aliis autoribus graphicè descriptum pro rei/ dignitate oculis subjicere tentaturus aliquid non/insulsum aut à veterum maiestate non alienum præstabit/sed Genio suo quisque indulgens musteum aliquid pro/Opimiano illo dulceamaro promet et injuriam magnis/illis manibus afferet, quos ego veneratione summa/ prosequor et vestigia euntium potius adoro quam vel sola/ cogitatione assequi me posse ingenuè profiteor."

130 Vell. 2, 7: „Hic est Opimius, a quo consule celeberrimum Opimiani vini nomen“ ('Die ist der Opimius, von dessen Konsulatsjahr der berühmte Wein seinen Namen hat.'). Lucius Opimius hat als Konsul auch dadurch Ruhm erlangt, dass in seiner Amtszeit 91 v. Chr. ein sehr gutes Weinjahr war. Vgl. auch Cic. Brut. 287; Plin. nat. XIV, 6 (55).

131 Vgl. Raupp 2000.

132 Peter Paul Rubens und Osias Beert d. Ä.: Pausias und Glycera. Öl auf Leinwand, $203,2 \times 194,3 \mathrm{~cm}$. Sarasota, Florida, The John and Mable Ringling Museum of Art. Vgl. Welzel 2000, 552 f.; Kat.-Ausst. Wien/Essen 2002, Nr. 33, 116 f.; Welzel 2002, 337-339. 


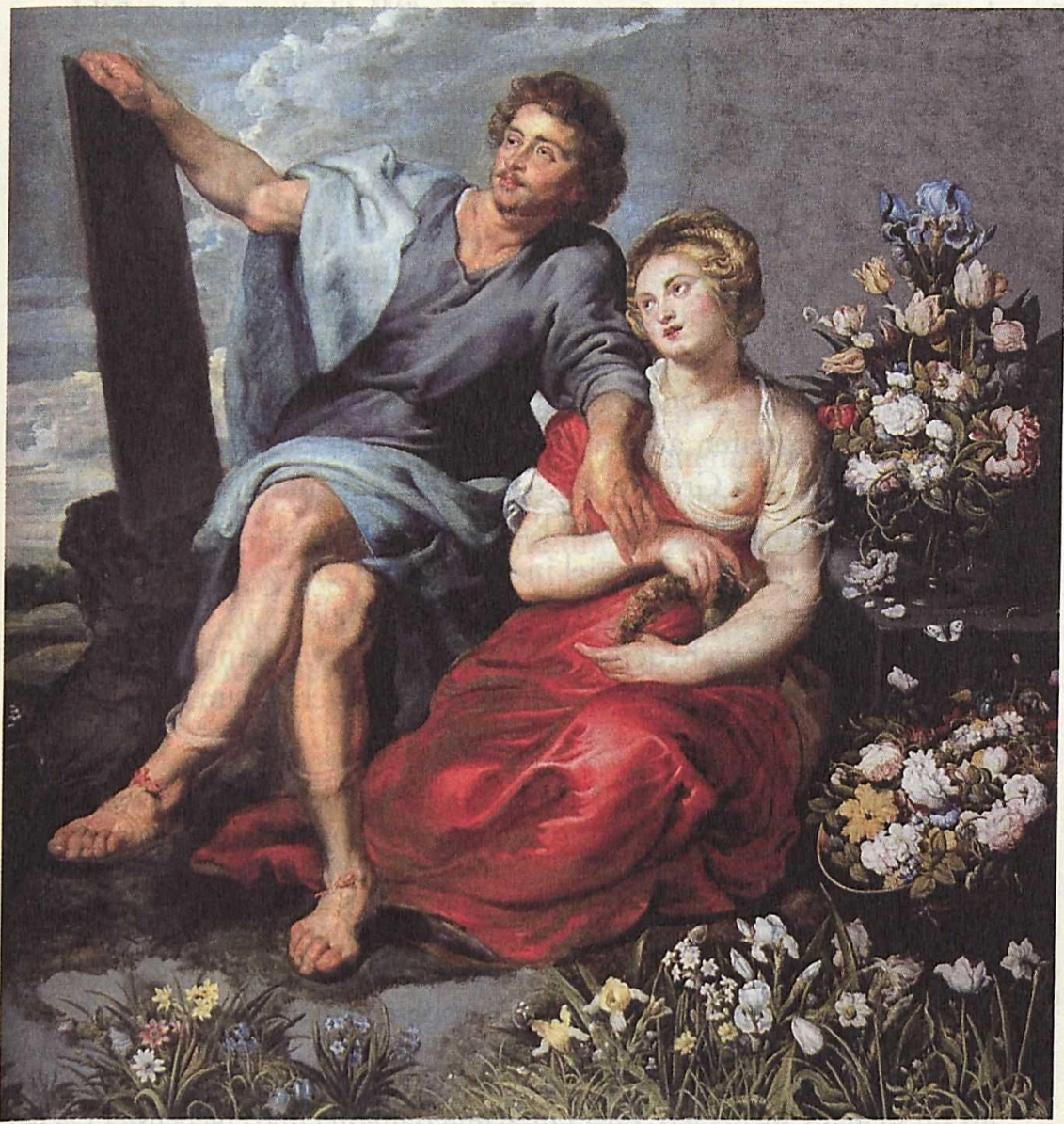

Abb. 6:

Peter Paul Rubens und Osias Beert d. Ä. (um 1612-1615): Pausias und Glycera. Öl auf Leinwand, 203,2 × 194,3 cm, Sarasota, Florida, The John and Mable Ringling Museum of Art.

Sie hatte antiker Überlieferung folgend die Kunst erfunden, Blumenkränze zu binden. Ihr Mann, der Maler Pausias, ,ahmte sie wetteifernd nach“, so Plinius in seiner Naturalis historia, ,und brachte es dadurch im Blumenmalen zur größten Mannigfaltigkeit. Endlich malte er auch sie selbst, wie sie mit einem Kranze dasitzt, und dieses Gemälde, eins seiner berühmtesten Bilder, erhielt den Namen 'Die Kranzflechterin' (stephanoplokos), bei anderen 'Die Kranzverkäuferin' (stephanopolis), weil Glycera in ihrer Armut durch den Verkauf von Kränzen ihren Lebensunterhalt bestritten hatte. Eine Kopie dieses Bildes, apographon genannt, kaufte Lucius Lucullus am 
Fest der Dionysien zu Athen für zwei Talente. ${ }^{(133}$ Als literarisches Bild war diese auch von Junius berichtete Erzählung, auf die 1604 in seinem Schilder-Boeck auch Karel Van Mander anspielt, durchaus präsent. ${ }^{134}$ Doch war Rubens der Erste, der sie in dieser Form ins Bild setzte. Ohne einen Vorläufer in der Bildtradition zu haben, griff Rubens in diesem Bild unmittelbar auf die antike Bildtradition zurück. Sein eigenes Bild wird zu dem, das Pausias gemalt hat, als er Glycera und ihre Kränze ins Bild setzte. ${ }^{135}$ Die Blumen in diesem Bild erweisen sich als gemalte Blumen, die mit denen des Malers Pausias in den Wettstreit treten. Was hier vorgeführt wird, ist mithin eine aemulatio mit einem gar nicht mehr greifbaren Prototyp. Das Aufgreifen antiker Bildbeschreibungen und der künstlerische Wettstreit mit den Großen der Antike hatte damals bereits eine lange Tradition, mit deren künstlerischen Resultaten Rubens vertraut war. Er hat sie fortgesetzt und ist, zum Beispiel in der Konkurrenz zu Tizian, auch mit dessen Auseinandersetzungen mit der antiken Malerei in den Wettstreit getreten. ${ }^{136}$ Das gilt es zu bedenken, wenn man die vermeintlich kritischen Passagen des Briefes liest, deren Zielrichtung sich nach einem Blick auf den Schluss des Briefes erschließt.

Ich bitte, mein Herr, mir all dies nicht übel aufzunehmen, was ich in freundschaftlichem Freimut gesagt habe, in der Hoffnung, dass Sie uns nach einer so guten Vorspeise nicht jenes Hauptgericht vorenthalten werden, nach dem uns allen sehr verlangt, denn bis jetzt hat noch niemand unseren Appetit gestillt, von all denen, die sich mit allsolcher Materie beschäftigt haben. Denn, wie ich schon sagte, man muss zu den einzelnen Persönlichkeiten kommen, womit ich mich von ganzem Herzen Euer Ehren guter Gunst empfehle, und mich nachdrücklich für die Ehre bedanke, die mir durch die Übersendung von Euer Ehren Buch und durch die Freundschaft zuteil geworden ist, bleibe ich in bis auf weiteres, mein Herr, Euer Ehren untertänigster und ergebenster Diener,

133 Plin. nat. 35, 125: ,amavit in iuventa Glyceram municipem suam, inventricem coronarum, certandoque imitatione eius ad numerosissimam florum varietatem perduxit artem illam. postremo pinxit et ipsam sedentem cum corona, quae e nobilissimis tabula est, appellata stephanoplocos, ab aliis stephanopolis, quoniam Glycera venditando coronas sustentaverat paupertatem. huius tabulae exemplar, quod apographon vocant, L. Lucullus duobus talentis emit Dionysius Athenis."

134 Junius 1637, 25, 135 (I, 4, \$1; III, 3, \$6). Vgl. auch Miedema 1973, Bd. 1, fol. $45^{\mathrm{r}-\mathrm{v}}$.

135 Welzel 2000, 553.

136 Beispiele hierfür bieten Rubens' Kopien nach Tizians Bacchanal der Andrier und dem Venusfest. Vgl. dazu zuletzt Görel Cavalli-Björkman, in: Kat.-Ausst. München 2009, 243-254, mit weiterer Literatur. 
Peter Paul Rubens.

Antwerpen, in großer Eile und stehenden Fußes, am 1. August $1637 .^{137}$

Die mit Bedacht gewählte Sprache des Briefes, sein Reichtum an literarischen Anspielungen und die augenscheinlich gründliche Durchsicht des Schreibens, die sich in Korrekturen und kleineren Verbesserungen erweist, steht im sichtbaren Widerspruch zu der am Schluss des Briefes behaupteten Eile. Sie vermochte nicht nur als potenzielle Entschuldigung für vielleicht übersehene Fehler zu dienen, die es nicht gibt, sondern bot dem Verfasser noch ein letztes Mal die Möglichkeit, „stans pede in uno“, Horaz zu zitieren und mit ihm einen besonders nachdrücklichen Verfechter der sinnlichen Anschaulichkeit heraufzubeschwören. ${ }^{138}$ Die lateinischen Einsprengsel im niederländischen Schlussteil des Briefes schlagen die Brücke zu der so nachdrücklich formulierten Aufforderung, diesem Buch weitere Ausführungen folgen zu lassen und „promulsidem“, der Vorspeise, „Ipsum caput cœnæ“, das Hauptgericht folgen zu lassen, „want tot noch toe en heeft ons niemandt onsen appetyt voldaen".

\section{9. „Nam oportet venire ad individua ut dixi“}

Auch Junius selbst war mit den Arbeiten seiner Vorgänger nicht zufrieden, wie er am 25. November 1634 seinen Freund Vossius in Amsterdam wissen ließ. „Ich habe Bulengers De pictura und andere Traktate zu diesem Thema gesehen, die mich allerdings nicht zufrieden stellen konnten ", schrieb er. ${ }^{139}$ Rubens, der Bulengers Traktat ebenfalls besaß, sah dies offensichtlich ähnlich, wobei er vor allem an der Konkretion der kunsttheoretischen

137 "Ick biddel mijn Heere believe my wel aftenehmen tgheene ick met / vriendelycke liberteyt ben seggende, met hope dat U.E. [dele] ons / naer soo goeden promulsidem niet en sal weygheren Ipsum/ caput cœnæ, daer allegader seer naer verlanghen/ want tot noch toe en heeft ons niemandt onsen appetyt/ voldaen van alle die ghene die alsulcken materie ghetracteert hebben/ nam oportet venire an individua ut dixi waermede ick gheb [iede] I my wt gantscher herten in U.E. [dele] goede gunste, ende grootelycx voor I de eere die my gheschiedt is met de presentatie van U.E. [dele] Boeck l ende vriendtschap bedanckende blijve in de eeuwigheijt, / Mijn Heere, / U.E. [dele] ootmoedighen ende

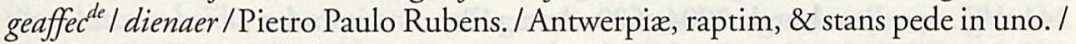
Den eersten Augusti 1637."

138 Hor. serm. I, 4, 10.

139 „Vidi Iul. Caes. Bulengeri, atque aliorum quorumdam super hac materia tractatulos; mihi tamen minime satisfacere potuerunt." van Romburgh 2004, $470 \mathrm{f}$., Nr. 95. Bei dem erwähnten Buch handelt es sich um: Jul. Caes. Bulengeri: De pictura, plastice, pp. libri duo. Leiden 1627; ebd., 471, Anm. 7. 
Überlegungen interessiert war. ${ }^{140}$ Das betont er auch in einer letzten lateinischen Wendung, die für das Verständnis dessen, was er von Junius zu lesen wünschte, besonders hilfreich ist. „Denn, wie ich schon sagte, man muss zu den einzelnen Persönlichkeiten kommen“, „Nam oportet venire ad individua ut dixi". "Wie ich gesagt habe", schreibt Rubens, doch war tatsächlich von den einzelnen Persönlichkeiten in diesem Brief noch gar nicht die Rede. Man kann deshalb vermuten, dass Rubens sich auf den Catalogus artificum bezog, das umfassende und vollständige Verzeichnis aller antiken Künstler, an dem Junius seinerzeit arbeitete. ${ }^{141}$ Dieser biographische Künstlerkatalog, in dem nicht nur alle antiken Maler und Bildhauer aufgeführt waren, sondern auch - dem klassischen techné-Begriff entsprechend - Ziseleure, Kupferschmiede, Töpfer, Mechaniker, Gold-, Silber- und Schwertschmiede, Steinmetze und Mathematiker, wurde zwar erst posthum publiziert, war aber im Zuge der Vorbereitungen zu den $D e$ pictura veterum libri tres angelegt worden. ${ }^{142}$ Rubens mag das gewusst haben, denn er stand schon um das Jahr 1612 mit Junius in Kontakt, dem er für seine Arbeit auch eine altenglische Glossenhandschrift zugänglich gemacht hatte. ${ }^{143}$ Doch lässt sich die Forderung, ,ad individua“ zu kommen, „zu den einzelnen Persönlichkeiten“, auch auf die weiter oben im Brief angemahnte Exemplifikation an italienischen Beispielen beziehen. Denn tatsächlich äußert sich Junius an verschiedenen Stellen seines Buches über die Malerei der Gegenwart. Wegen seines kompilierenden Schreibstils ist im Kontext der angehäuften Zitate nicht immer deutlich, ob er von seiner eigenen Gegenwart schreibt oder von der Gegenwart des von ihm heraufbeschworenen klassischen Zeitalters. Diese Unklarheit war sicherlich gewollt, denn sie macht es möglich, alles Gesagte auf die Gegenwart des Lesers zu beziehen. So schreibt Junius beispielsweise, dass man sich nicht wundern müsse, dass es auf dem Felde der Kunst so wenige Meister gebe, „da diese Kunst aus lauter Sachen besteht, in deren jeglicher weit zu

140 „Bulengerus de Pictura Plasticæ Statuaria.“ In einem Exemplar im Nachlass von Albert Rubens nachgewiesen. Vgl. Arents 2001, 352, fol. 14, kol. 2.

141 Vgl. van Romburgh 2004, 600, Anm. 12.

142 Junius 1694, 10: „Alcon, Cælator“, 11: „Alexander, Ærarius Faber“, 12: „Ampelius, Figulus“, 14: „Anthemius, Mechanicus“, 16: „Antigonus, Argentarius“, 25 : „Archaicus, Faber“, 26: „Architeles, Lapicida“, 32: „Asius, Mathematicus“.

143 Auf einen frühen Kontakt zwischen Junius und Rubens schon um 1612 weist Howarth 1985, 150, hin. Zu dem frühen Kontakt der beiden vgl. auch Heinen 1996, 22. 
kommen sehr viel heißt“. ${ }^{144}$ Man erstaune, so Junius, über die Frechheit jener völlig ungebildeten Maler, die mithin ohne die geringste Kenntnis der notwendigsten theoretischen Grundlagen ihre Kunst ausüben und für die gelte, was Martial über die schlechten Dichter sage: „Nichts ist sorgloser, als ein schlechter Poet". ${ }^{145}$

Denn gegenwärtige Künstler bieten uns, welch ein gräulicher schändlicher Fehler, die gemeinsten abgedroschensten Erfindungen dar, und indem sie das Studium der Weisheit und die Vorschriften Verständiger hintan setzen, schränken die gleichsam aus ihrem Reiche vertriebene Kunst bloß auf wenige Sinne und in die allerengsten Grenzen ein. ${ }^{146}$

Wirklich gute Bilder könnten nur jene schaffen, so Junius, die ,alles, was sie in ihrer erhabenen Seele entwerfen, ohne Schwierigkeit auf die Leinwand bringen und dem Zuschauer vor Augen stellen können. Denn wenn ein Künstler es nicht so weit gebracht hat, wird seine Arbeit gänzlich vergebens, und alles Hervorgebrachte einem Schwert zu vergleichen sein, das verborgen in der Scheide steckt. Das also muss man vornehmlich lernen.

144 „Desinamus igitur mirari, quæ causa sit artificum paucitatis, cùm ex is rebus universis hæc ars constet, quibus in singulis elaborare permagnum est." Junius 1637 (III, 1, \$16), 152 f.; Junius 1641 (III, 1, \$16), 239 f.: „Het en verdient oversulcks gheen groote verwonderinghe, dat de goede Konstenaers huydensdaeghs soo dunne ghesaeyt sijn; vermids dese Konste de hulpe van ettelicke andere diepe Konsten ende wetenschappen vereyscht; soo dat een redelick verstand gheoordeelt [240:] wordt sich wel ghequeten te hebben, als het maer in eene deser wetenschappen kann uytmunten. Daerom plaghten ook d'oude Meesters, die nae de volmaecktheyd stonden, haer selven voor gheen Konstenaers uyt te gheven, 't en waer saecke dat sy haer leersaem gemoed met een alghemeyne kennisse van verscheyden andere Konsten ende wetenschappen tot dese Konst behoorlicker wijse hadden voorbereydet."

145 „Non quidem latet me plures esse, qui communi eruditione satis superque imbuti, contemnunt potius litteras quàm nesciunt; tanquam majorem industriæ \& laboris gloriam habituri, si ingenium eorum nullis alienarum artium adminiculis inniti videretur; cæterùm hos ex antiquitatis vestigiis malè dissimulatis statim deprehendere licebit. illorum potius hominum os miremur, qui ad tantam artem sine ullâ rerum necessarium scientiâ audent accedere; cùm ne quidem communia illa \& protrita humaniorum disciplinarum præcepta primoribus labris delibasse deprehendantur; tantum abest ut unquam eruditum illum pulverem, qui maxima artibus hisce subsidia subministrat, attingerint. usque adeò in malos quoque Pictores quadrat illud Martialis, Nil securius est malo poëtâ. “Junius 1637, 153 (III, 1, \$16).

146 „Quod adeo negligitur ab horum temporum artificibus, ut in operibus eorum foedo ac pudendo vitio trivialium Inventionum fæces deprehendantur; dumque sapientiæ studium \& præcepta prudentium penitùs reformidant, in paucissimos sensus \& augustissimos limites augustam detrudunt artem." Junius 1637, 153 (III, 1, $\$ 15)$. 
Hierzu kann niemand ohne Kunst gelangen, hiernach muss man mit allem Fleiß streben. ${ }^{\text {"147 }}$ Zumindest das von Junius geforderte stete Bestreben dürfte Rubens fraglos für sich in Anspruch genommen haben. Als Maler mit einem hohen auch theoretisch begründeten Anspruch an die eigene Kunstproduktion musste Rubens gerade für derartige auf die „gegenwärtigen Künstler“, „horum temporum artifices“, bezogene Aussagen sensibel und empfänglich sein. Deutlich erweist zum Beispiel Rubens' posthum gedruckter Traktat über die Nachahmung der Statuen, wie stark Rubens sich um die künstlerische Realisierung antiker Qualitätsansprüche bemühte. ${ }^{148}$ Eine Präzisierung der von Junius' geäußerten Kritik an den Malern der Gegenwart, wenn nicht gar eine positiv gestimmte Würdigung seines eigenen Bemühens, musste Rubens also ein echtes Anliegen sein. „Nam oportet venire ad individua" lässt sich mit Blick auf Rubens' Ausführungen als Aufforderung lesen, die in den De pictura veterum libri tres zusammengetragenen Kunsttopoi in der ästhetischen Rezeption zeitgenössischer Kunst, vor allem der italienischen Malerei, genauer darzustellen. Doch dieser Ausführungen bedurfte es gar nicht, wenn man alles, was Junius dargelegt hatte, unmittelbar auf die zeitgenössische Kunst bezog.

Indem Rubens' Brief den späteren Ausgaben des Buches vorangestellt wurde, sowohl der niederländischen Ausgabe von 1641 als auch der lateinischen Neuausgabe von 1694, wurde er zu einer aus berufenem Mund geäußerten Leseanweisung. Als weithin für seine Kunst wie für seine Bildung bewunderter Maler, "quod experti dicimus“, legte Rubens dem Leser von Junius' Buch nahe, ihre Haltung zur Rezeption aktueller Kunst an den antiken Topoi und Kriterien auszurichten, die Rubens selbst sowohl in seiner Kunst als auch in seinen theoretischen Äußerungen zum Ausdruck gebracht hatte. Mit seiner Rekonstruktion einer antiken Wirkungsästhetik hatte Junius die in Rubens' Kunstpraxis wie in dessen theoretischen Überlegungen greifbaren Ideale begründet und beschrieben. Die Depictura veterum libri tres bedeuteten nichts weniger als die Erläuterung und die Rationalisierung dessen, was Rubens, wie nicht zuletzt seine Werke bezeugen, als die zentrale Aufgabe seiner künstlerischen Praxis sah. Es liegt

147 „Neque enim tales rectè dixeris pingere; quod eorum tantum est poprium, qui omnia, quæ sublimi conceperit animo, expeditè quoque promere atque ad spectaturos perferre valent. Illud enim isi assecutus fuerit artifex, supervacuo tantum labori insudaverit, ac priora omnia similis sunt gladio conditio atque intra vaginam suam hærenti. Hoc enim maxim è docetur; hoc nullus nisi arte adsequi potest." Junius 1637, 153 (III, $1, \$ 15$ ).

148 Auf diesen jüngst in bewundernswerter Präzision analysierten Traktat muss an dieser Stelle nicht weiter eingegangen werden. Vgl. dazu Thielemann [im Druck]. 
deshalb nahe, die in seinem Euvre zahlreichen Zeugnisse für den Wettstreit mit anderen Malern mit dem von Junius präzise definierten und als Paradigma etablierten Begriff der aemulatio zu beschreiben.

\section{Bibliographie}

Aldrich, Keith/Fehl, Philipp/Fehl, Raina (Hrsg.) (1991): Franciscus Junius: The literature of classical art. 2 Bde. Berkeley u. a.: University of California Press. Arents, Prosper (2001): De Bibliotheek van Pieter Pauwel Rubens: een reconstructie. Hrsg. von Alfons K.L. Thijs. Antwerpen: Vereniging der Antwerpse Bibliofielen.

Baglione, Giovanni (1642): Le vite de pittori, scultori et architetti. Dal Pontificato di Gregorio XIII. del 1572. In fino a'tempi di Papa Vrbano ottauo nel 1642. Rom: Fei.

Barner, Wilfried (Hrsg.) (1989-2001): Gotthold Ephraim Lessing. Werke und Briefe. 12 Bde. Frankfurt a.M.: Deutscher Klassiker-Verlag.

Baudouin, Frans (1995): „Peter Paul Rubens en Galileo Galilei: Een minder bekende bladzijde uit de Europese cultuurgeschiedenis", in: Studia Europea. Koninklijke Academie voor Wetenschappen, Letteren en Schone Kunsten van België 1, 69-94.

Bellori, Giovanni Pietro (1672): Le vite dé pittori, scultori et architetti moderni, parte prima. Rom: Mascardi.

Biagioli, Mario (1999): Galilei, der Höfling. Endeckung und Etikette. Vom Aufstieg der neuen Wissenschaft. Frankfurt a.M.: S. Fischer.

Biographie Nationale (1866-1986): Academie royale des sciences, des lettres et des beaux-arts de Belgique. $44 \mathrm{Bde}$. Brüssel: Academie royale.

Bomford, Kate (2000): The Visual Representation of Friendship amongst Humanists in the Southern Netherlands. c. 1560 - c. 1630. [Dissertation, University of London, Courtauld Institute of Art, London (Typoskript)] .

Brown, Beverly Louise (2001): „Die schwarzen Schwingen des Neides: Konkurrenz, Rivalität und Vorbild“, in: Kat.-Ausst. London (2001): Die Geburt des Barock. Hrsg. von Beverly Louise Brown. Ausst. London, Royal Academy of Arts, 20. Januar - 1.6. April 2001. Stuttgart: Belser.

Brown, Christopher (1998): „Rubens and the Archdukes“, in: Thomas, Werner/ Duerloo, Luc (Hrsg.): Albert \& Isabella 1598-1621: Essays. Turnhout: Brepols.

Büttner, Nils (2002a): „'...is said to follow the light of the Sun' - Van Dycks Selbstbildnis mit der Sonnenblume", in: Zeitschrift für Kunstgeschichte 65, 2442.

Büttner, Nils (2002b): „Arents / Thijs: De Bibliotheek van Pieter Pauwel Rubens: een reconstructie", in: Kunstform 3:10, URL: http://www.sehepunkte.de/ 2002/10/3203.html [letzter Zugriff: 06.Oktober 2010].

Büttner, Nils (2006): Herr P. P. Rubens: Von der Kunst, berübmt zu werden. Göttingen: Vandenhoeck \& Ruprecht. 
Carpenter, William Hookham (1844): Pictorial notices consisting of a memoir of Sir Anthony Van Dyck, with a descriptive catalogue of the etchings executed by him: and a variety of interesting particulars relating to other artists patronized by Charles I. Collected from documents in Her Majesty's State Paper Office, the Office of Public Records, and other sources. Cambridge: Chadwyck-Healey.

De Maeyer, Marcel (1955): Albrecht en Isabella en de schilderkunst. Brüssel: Paleis der Academien.

Dundas, Judith (2007): Sidney and Junius on poetry and painting. From the Margins to the Center. Newark: University of Delaware Press.

Ellenius, Allan (1960): De Arte Pingendi: Latin literature in seventeenth century Sweden and its international background. Uppsala: Almquist \& Wiksell.

Emmens, Jan A. (1979-1981): Verzameld werk. 4 Bde. Amsterdam: van Oorschot.

Evers, Hans Gerhard (1942): Peter Paul Rubens. München: Bruckmann.

Fabri, Felix (1605): Historia Suevorum. Hrsg. von Melchior Goldast. Frankfurt a.M.: Richter.

Fehl, Philipp (1998): „Access to the Ancients: Junius, Rubens and Van Dyck“, in: Bremmer, Rolf H. (Hrsg.): Franciscus Junius F. F. and his circle. Amsterdam u. a.: Rodopi, $35-70$.

Fiorillo, Johann Dominik (1815-1820): Geschichte der zeichnenden Künste in Deutschland und den vereinigten Niederlanden. 4 Bde. Hannover: Hahn.

Génard, Pieter (1877): P. P. Rubens, Aantekeningen over den grooten Meester en zijne bloedverwanten. Antwerpen: Kockx.

Goeler von Ravensburg, Friedrich (1882): Rubens und die Antike. Jena: Costenoble.

Grafton, Anthony (1983): Joseph Scaliger: A Study in the History of Classical Scholarship. 2 Bde. Oxford: Clarendon Press.

Grubinus, Oporinus (1611): Amphotides Scioppianae. Paris.

Heinen, Ulrich (1996): Rubens zwischen Predigt und Kunst: Der Hochaltar für die Walburgenkirche in Antwerpen. Weimar: VDG.

Heinen, Ulrich (2001): „Haut und Knochen - Fleisch und Blut. Rubens' Affektmalerei", in: Heinen, Ulrich/Thielemann, Andreas (Hrsg.): Rubens Passioni - Kultur der Leidenschaften im Barock. Göttingen: Vandenhoeck \& Ruprecht, 70-109.

Heinen, Ulrich (2002): ,'Versatissimus in historiis et re politica': Rubens' Anfänge als Diplomat", in: Wallraf-Richartz-Jahrbuch 63, 283-318.

Heinen, Ulrich (2009): „Stoisch trauern: Bewältigungsstrategien bei Peter Paul Rubens", in: Bogner, Ralf Georg/Steiger, Johann Anselm/Heinen, Ulrich (Hrsg.): Leichabdankung und Trauerarbeit. Zur Bewältigung von Tod und Vergänglichkeit im Zeitalter des Barock. Amsterdam/New York: Rodopi, 119180.

Hennen, Christiane (1995): „Karl zu Pferde“: Ikonologische Studien zu Anton van Dycks Reiterporträts Karls I. von England. Frankfurt a.M.: Lang.

Howarth, David (1985): Lord Arundel and his Circle. New Haven/London: Yale University Press. 
Hübner, Gert (2010): „Evidentia’: Erzählformen und ihre Funktion“, in: Haferland, Harald u.a. (Hrsg.): Historische Narratologie - Mediävistische Perspektiven. Berlin/New York: De Gruyter.

Huemer, Frances (1985): „Philip Rubens and his brother the painter", in: Balis, Arnout u. a. (Hrsg.): Rubens and his World. Bijdragen opgedragen aan Prof. Dr. Ir. R.-A. d'Hulst. Antwerpen: Het Gulden Cabinet, 123-128.

Huemer, Frances (1996): Rubens and the Roman circle. Studies of the first decade. New York/London: Garland.

Jaffé, David (1996): „Earl and Countes of Arundel: Renaissance Collectors“, in: Apollo 144, 9-11.

Jaffé, Michael (1977): Rubens and Italy. Oxford: Phaidon.

Junius, Franciscus (1637): De Pictura veterum libri tres. Amsterdam: Blaev.

Junius, Franciscus (1641): De Schilder-Konst der Oude, Begrepen in drie Boecken. Middelburgh: Roman.

Junius, Franciscus (1694): Catalogus, adbuc ineditus, architectorum, mechanicorum, sed praecipue pictorum, statuariorum, caeletorum, tornatorum aliorumque artificum et operum quae fecerunt, secundum seriem litteratum digestus. Rotterdam: Leers.

Kat.-Ausst. Antwerpen/London (1999): Van Dyck 1599-1641. Hrsg. von Christopher Brown und Hans Vlieghe. Ausst. Antwerpen, Koninklijk Museum voor Schone Kunsten, 15. Mai - 15. August 1999; London, Royal Academy of Arts, 11. September - 10. Dezember 1999. New York u. a.: Rizzoli.

Kat.-Ausst. Braunschweig (2004): Peter Paul Rubens: Barocke Leidenschaften. Hrsg. von Nils Büttner und Ulrich Heinen. Ausst. Braunschweig, Herzog Anton Ulrich-Museum, 8. August - 31. Oktober 2004. München: Hirmer.

Kat.-Ausst. Canberra (1988): Rubens' Self-portrait in focus. Hrsg. von David Jaffé. Ausst. Canberra, Australian National Gallery, 13. August -30. Oktober 1988. Brisbane: Boolarong.

Kat.-Ausst. Köln (1977): Peter Paul Rubens 1577-1640, Katalog I. Ausst. Köln, Wallraf-Richartz-Museum, 15. Oktober - 15. Dezember. Köln: Greven \& Bechtold.

Kat.-Ausst. Köln (1992): Von Bruegel bis Rubens: Das goldene Jabrhundert der flämischen Malerei. Hrsg. von Ekkehard Mai und Hans Vlieghe. Ausst. Köln, Wallraf-Richartz-Museum, 4. September - 22. November 1992. Köln: Dumont.

Kat.-Ausst. Lille (2004): Rubens. Ausst. Lille, Palais des Beaux-Arts, 6. März 14. Juni 2004. Stuttgart: Belser.

Kat.-Ausst. München (2009): Rubens im Wettstreit mit Alten Meistern: Vorbild und Neuerfindung. Hrsg. von Reinhold Baumstark und Miriam Neumeister. Ausst. München, Alte Pinakothek, 23. Oktober 2009-7. Februar 2010. Ostfildern: Hatje Cantz.

Kat.-Ausst. Wien (2004): Peter Paul Rubens. Hrsg. von Anne-Marie Logan. Ausst. Wien, Graphische Sammlung Albertina, 15. September - 5. Dezember. Ostfildern: Hatje Cantz.

Kat.-Ausst. Wien/Essen (2002): Das flämische Stillleben 1550-1680. Hrsg. von Wilfried Seipel. Ausst. Wien, Kunsthistorisches Museum, 18. März - 21. Juli 
2002; Essen, Kulturstiftung Ruhr, Villa Hügel, 1. September - 8. Dezember 2002. Lingen: Luca-Verlag.

Kayling, Annegret (2003): Poussins Kunstauffassung im Kontext der Philosophie: Eine Interpretation des Louvreselbstbildnisses unter Berücksichtigung seiner Briefe und seines Oeuvre. Marburg: Tectum.

König, Eberhard/Schön, Christiane (1996): Stilleben. Berlin: Reimer (= Geschichte der klassischen Bildgattungen in Quellentexten und Kommentaren, 5).

Lee, Rensselaer W. (1967): Ut pictura poesis. The Humanistic Theory of Painting. New York: Norton.

Lipsius, Justus (1675): Justi Lipsii v. c. opera omnia postremum ab ipso aucta et recensita: nunc primum copioso rerum indice illustrata. 4 Bde. Wesel: Hoogenhuysen.

Magurn, Ruth Saunders (Hrsg.) (1971): The letters of Peter Paul Rubens. Cambridge, Mass.: Harvard University Press.

McGrath, Elizabeth (1997): Rubens. Subjects from History. 2 Bde. London: Miller (= Corpus Rubenianum Ludwig Burchard, 13).

Miedema, Hessel (Hrsg.) (1973): Karel Van Mander: Den grondt der edel vrij schilder-const. 2 Bde. Utrecht: Haentjens Dekker \& Gumbert.

Morford, Mark (1991): Stoics and Neostoics. Rubens and the Circle of Lipsius. Princeton: University Press.

Müller Hofstede, Justus (1966): „Zu Rubens' zweitem Altarwerk für Sta. Maria in Vallicella", in: Nederlands Kunsthistorisch Jaarboek 17, 1-78.

Müller Hofstede, Justus (1977): „Rubens und die niederländische Italienfahrt: Die humanistische Tradition“, in: Kat.-Ausst. Köln 1977, 21-37.

Nativel, Colette (1988): „La comparaison entre la peinture et la poésie dans le 'de

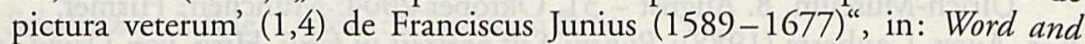
Image 4, 323-330.

Nativel, Colette (1989): „Quelques sources antiques du 'De Pictura Veterum' de Franciscus Junius", in: De zeventiende eeuw 5, 33-49.

Nativel, Colette (Hrsg.) (1996): Franciscus Junius: De pictura veterum. Hrsg., komm. und übers. von Colette Nativel. Genf: Droz.

Nativel, Colette (1998): „A Plea for Junius as an Art Theorician“ in: Bremmer, Rolf, H. (Hrsg.): Franciscus Junius F. F. and his circle. Amsterdam u. a.: Rodopi, 19-33.

Nativel, Colette (2009): „Ut pictura poesis: Junius et Roger de Piles“, in: XVII siècle 61, 593-608.

Neumeister, Sebastian (1998): „Kaspar Schoppe im Urteil der Aufklärung (Pierre Bayle)", in: Jaumann, Herbert (Hrsg.): Kaspar Schoppe (1576-1649). Philologe im Dienste der Gegenreformation. Beiträge zur Gelehrtenkultur des europäischen Späthumanismus. Frankfurt a.M.: Klostermann, 380-390 (= Zeitsprünge. Forschungen zur Frühen Neuzeit 2, Heft 3/4).

O’Neil, Maryvelma (1996): Art. „Baglione“, in: Turner, Jane (Hrsg.): The Dictionary of Art. 36 Bde. New York: Grove, Bd. 3, 53-55.

Peeters, Hugo (1999): „Le 'Contubernium' de Lipse à Louvain à travers sa correspondance", in: Tournoy, Gilbert (Hrsg.): Iustus Lipsius, europae lumen et 
columen: proceedings of the international colloquium, Leuven, 17. - 19. September 1997. Leuven: Leuven University Press, 141-168.

Pfisterer, Ulrich (1996): „Künstlerische Potestas audendi und Licentia im Quattrocento: Benozzo Gozzoli, Andrea Mantegna, Bertoldo di Giovanni“, in: Römisches Jahrbuch der Bibliotheca Hertziana 31, 107-148.

Raupp, Hans-Joachim (1984): Untersuchungen zu Künstlerbildnis und Künstlerdarstellung in den Niederlanden im 17. Jahrbundert. Hildesheim u. a.: Olms.

Raupp, Hans-Joachim (2000): „Rubens und das Pathos der Landschaft“, in: Heinen, Ulrich/Thielemann, Andreas (Hrsg.): Rubens Passioni. Die Kultur der Leidenschaften im Barock. Göttingen: Vandenhoeck \& Ruprecht, 159-179.

Romburgh, Sophia Georgina van (2004): For my worthy friend Mr. Franciscus Junius. An edition of the correspondence of Francis Junius F.F. (1591-1677). Leiden u. a.: Brill.

Rooses, Max (1903): Rubens' Leven en Werken. Amsterdam: Uitgevers-Maatschappy Elsevier.

Rooses, Max/Ruelens, Charles (1887-1909): Correspondance de Rubens et Documents Epistolaires concernant sa Vie et ses Euvres Publies. Codex Diplomaticus Rubenianus. 6 Bde. Antwerpen: De Backer u.a.

Rubens, Philipp (1608): Electorvm libri II. In quibus antiqui ritus, emendationes, censura. Eivsdem ad Ivstum Lipsivm Poëmatia. Antwerpen: Plantin.

Sainsbury, Noël W. (1859): Original Unpublished Papers illustrative of the life of Sir Peter Paul Rubens. London: Bradbury \& Evans.

Scavizzi, Giuseppe (1989): „The cross: A 16th century controversy“, in: Storia dell'arte 65, 27-43.

Schlosser, Julius von (1924): Die Kunstliteratur: Ein Handbuch zur Quellenkunde der neueren Kunstgeschichte. Wien: Schroll.

Schönberger, Otto (Hrsg.) (1990): M. Tullius Cicero: Pro A. Licinio Archia poeta oratio. Stuttgart: Reclam.

Schöne, Albrecht ( $\left.{ }^{3} 1993\right)$ : Emblematik und Drama im Zeitalter des Barock. 3. Aufl. mit Anmerkungen. München: Beck.

Simoni, Simone (1566): In librum Aristotelis, peri tōn aisthètēriōn kai tōn aisthētōn: Hoc est, de sensuum instrumentis \& de his quae sub sensum cadunt, commentarius. Genf: Crispin.

Stewart, J. Douglas (1990): „'Death Moved Not His Generous Mind': Allusions and Ideas, Mostly Classical, in Van Dyck's Work and Life", in: Kat.-Ausst. Washington: Anthony Van Dyck: Paintings. Hrsg. von Arthur K. Wheelock, Susan J. Barnes und Julius Held. Ausst. Washington, National Gallery of Art, 11. November 1990-24. Februar 1991. New York: Abrams, 69-74.

Thielemann, Andreas (2011): „Rubens' Traktat 'De imitatione statuarum'“, in: Bredekamp, Horst (Hrsg.): Imitatio als Transformation, Akten des Internationalen Kolloquiums, Berlin 2008 [im Druck].

Van de Velde, Carl (2006): „Rubens' brieven in het Nederlands“, in: Van der Stighelen, Katlijne (Hrsg.): Munuscula amicorum. Turnhout: Brepols, 147183.

Van der Meulen, Marjon (1994-1995): Rubens. Copies After the Antique. 3 Bde. London: Harvey Miller (= Corpus Rubenianum Ludwig Burchard, 23). 
Van der Poel, Marc (1999): „Lipsius as a Defender of Plautus“, in: Iustus Lipsius, europae lumen et columen: proceedings of the international colloquium, Leuven, 17. - 19. September 1997. Hrsg. von Gilbert Tournoy. Leuven: University Press, $179-185$.

Van Mander, Karel (1604): Het Schilder-Boeck. Haarlem: van Wesbusch.

Vatteroni, Sergio (2004): „Note sulla terminologia della retorica nel 'Tresor' di Brunetto Latini", in: Ferluga-Petronio, Fedora (Hrsg.): Intersezioni plurilingui nella letteratura medioevale e moderna. Rom: Calamo, 147-156.

Vlieghe, Hans (1972): Rubens. Saints. 2 Bde. Brüssel: Arcade (= Corpus Rubenianum Ludwig Burchard, 8).

Vöhringer, Christian (Hrsg.) (2010): Kunstliteratur der Neuzeit: eine kommentierte Anthologie. Darmstadt: Wissenschaftliche Buchgesellschaft.

Wängler, Johann Philipp (1617): „Joh. Philippi Parei Electa Plautina in quibus velut thesauro quodam antiquitatis, quicquid est rerum memorabilium, rituumq[ue] Romanorum", in: Comicorum Latinorum principe M. Accio Plauto: sub Universales Titulos Locorum Communium refertur. Varii Item Authores, Qua Graeci, qua Latini, paßim illustrantur, \& explicantur. Frankfurt: Rosa.

Warnke, Martin (1965): Kommentare zu Rubens. Berlin: De Gruyter.

Warnke, Martin (1991): „Kunst vor ihrer Geschichte. Zum kunsthistoriographischen Verfahren des Franciscus Junius", in: Ganz, Peter u.a. (Hrsg.): Kunst und Kunsttheorie. 1400-1900. Wiesbaden: Harrassowitz, 135-143.

Welzel, Barbara (2000): „Kunstvolle Inszenierung von Natürlichkeit. Anmerkungen zu den Blumenstilleben von Jan Brueghel d.Ä.", in: Laufhütte, Hartmut (Hrsg.): Künste und Natur in Diskursen der Frühen Neuzeit. 2 Bde. Wiesbaden: Harrassowitz (= Wolfenbütteler Arbeiten zur Barockforschung, 35), Bd. 1, 549-560.

Welzel, Barbara (2002): „Wettstreit zwischen Kunst und Natur. Die Blumenstilleben von Jan Brueghel d. Ä. als Triumph des Bildes", in: Zeitschrift für Kunstgeschichte 65, 325-342.

Westfehling, Uwe (2001): „Drei verschollene Zeichnungen von Peter Paul Rubens", in: Wallraf-Richartz-Jahrbuch 62, 171-222.

Zoff, Otto (Hrsg.) (1918): Die Briefe des P. P. Rubens. Übersetzt und eingeleitet. Wien: Schroll.

zur Mühlen, Ilse von (1990): „Nachtridentinische Bildauffassungen: Cesare Baronio und Rubens' Gemälde für Maria in Vallicella in Rom", in: Münchner Jahrbuch der Bildenden Kunst 41, 23-60. 


\section{Abbildungsnachweise:}

Abb. 1:

Abb. 2:

Abb. 3:

Abb. 4:

Abb. 5:

Abb. 6:
Archiv des Verfassers.

Archiv des Verfassers.

Archiv des Verfassers.

Archiv des Verfassers.

Archiv des Verfassers.

Archiv des Verfassers. 